\title{
Brain network mechanisms of visual perceptual organization in schizophrenia and bipolar disorder
}

Brian P. Keane ${ }^{1,2}$, Bart Krekelberg ${ }^{3}$, Ravi D. Mill ${ }^{3}$, Steven M. Silverstein ${ }^{1,2,4}$, Judy L. Thompson ${ }^{1,2}$, Megan R. Serody ${ }^{1,2}$, Deanna M. Barch ${ }^{5^{*}}$, Michael W. Cole ${ }^{3^{*}}$

${ }^{1}$ University Behavioral Health Care, Department of Psychiatry, and Center for Cognitive Science, Rutgers, The State University of New Jersey,

Piscataway, NJ 08854, USA

${ }^{2}$ Departments of Psychiatry and Neuroscience, University of Rochester Medical Center, 601 Elmwood Ave, Rochester, NY 14642, USA

${ }^{3}$ Center for Molecular and Behavioral Neuroscience, Rutgers, The State University of New Jersey, 197 University Ave, 07102, USA

${ }^{4}$ Department of Ophthalmology, University of Rochester Medical Center, 601 Elmwood Ave, Rochester, NY, USA

${ }^{5}$ Departments of Psychological \& Brain Sciences, Psychiatry, and Radiology, Washington University in St. Louis, One Brookings Drive, St. Louis, MO 63130, USA

\section{${ }^{*}$ Co-senior authors}

Dedications: None.

Corresponding Author: brian_keane@urmc.rochester.edu

Number of pages: 50

Number of figures: 6

Number of tables: 2 Tables +3 Extended Data Tables

Word count for abstract: 250

Word count for introduction: 649

Word count for discussion: 1497

Conflict of Interest: The authors declare no competing conflicts of interest. 
medRxiv preprint doi: https://doi.org/10.1101/2022.01.26.22269913; this version posted January 28, 2022. The copyright holder for this preprint (which was not certified by peer review) is the author/funder, who has granted medRxiv a license to display the preprint in perpetuity. It is made available under a CC-BY-NC-ND 4.0 International license.

\section{ABNORMAL BRAIN NETWORKS OF PERCEPTUAL ORGANIZATION}

\section{Acknowledgments}

We thank Rebekah Boy, Laura Crespo, Lisa Cruz, Blair Singer, and Dillon Smith for help in recruiting participants and collecting and organizing study data. We are also indebted to Michael Harms for assistance in finalizing the pulse sequence, Pamela Butler for assistance in patient recruitment, and Takuya Ito and Carrisa Cocuzza for providing sample code. The authors additionally acknowledge the Office of Advanced Research Computing (OARC) at Rutgers University for providing access to the Amarel cluster and associated research computing resources (http://oarc.rutgers.edu). This work was supported by a National Institutes of Health Mentored Career Development Award (K01MH108783) to BPK. 
medRxiv preprint doi: https://doi.org/10.1101/2022.01.26.22269913; this version posted January 28, 2022. The copyright holder for this preprint (which was not certified by peer review) is the author/funder, who has granted medRxiv a license to display the preprint in perpetuity. It is made available under a CC-BY-NC-ND 4.0 International license .

\title{
ABNORMAL BRAIN NETWORKS OF PERCEPTUAL ORGANIZATION
}

\begin{abstract}
Visual shape completion is a canonical perceptual process that integrates spatially distributed edge information into unified representations of objects. People with schizophrenia show difficulty in discriminating completed shapes but the brain networks and functional connections underlying this perceptual difference remain poorly understood. Also unclear is whether similar neural differences arise in bipolar disorder or vary across the schizo-bipolar spectrum. To address these topics, we scanned (fMRI) people with schizophrenia, bipolar disorder, or no psychiatric illness during rest and during a task in which they discriminated configurations that formed or failed to form completed shapes (illusory and fragmented condition, respectively). Illusory/fragmented task activation differences ("modulations"), resting-state functional connectivity, and multivariate pattern differences were identified on the cortical surface using 360 predefined parcels and 12 functional networks composed of such parcels. Brain activity flow mapping was used to evaluate the likely involvement of resting-state connections for shape completion. Dorsal attention network modulations distinguished people with schizophrenia (AUCs>.85) and could trans-diagnostically predict cognitive disorganization severity. Activity flow over functional connections from the dorsal attention network could predict secondary visual network modulations in each group, except among those with schizophrenia. Task modulations among patients were more heterogeneous and dispersed over a larger number of networks compared to controls. In summary, abnormal dorsal attention network activity emerges during perceptual organization in schizophrenia and may be related to improper attention-related feedback into secondary visual areas. Patients with either disorder may compensate for abnormal perception by an idiosyncratic recruitment of regions across multiple non-visual networks.
\end{abstract}

Keywords: dorsal attention network, resting-state functional connectivity, Kanizsa shapes, subjective contours 
medRxiv preprint doi: https://doi.org/10.1101/2022.01.26.22269913; this version posted January 28, 2022. The copyright holder for this preprint (which was not certified by peer review) is the author/funder, who has granted medRxiv a license to display the preprint in perpetuity. It is made available under a CC-BY-NC-ND 4.0 International license.

\section{ABNORMAL BRAIN NETWORKS OF PERCEPTUAL ORGANIZATION}

Significance Statement: Perceptual organization is impaired in schizophrenia and possibly bipolar disorder. What brain networks might be responsible? We addressed this question by scanning (fMRI) healthy controls, bipolar disorder patients, and schizophrenia patients as they discriminated configurations that formed or failed to form visually completed shapes. Dorsal attention network activity was distinctive in the schizophrenia group and was related to cognitive disorganization severity across disorders. In both patient groups, neural representations of shape completion were more heterogeneous and distributed through more networks compared to controls. We suggest that abnormal perceptual organization in schizophrenia may arise from inadequate attention-related feedback from dorsal attention to secondary visual areas and, more speculatively, that patients in either group may compensate by relying on additional non-visual networks. 
medRxiv preprint doi: https://doi.org/10.1101/2022.01.26.22269913; this version posted January 28, 2022. The copyright holder for this preprint (which was not certified by peer review) is the author/funder, who has granted medRxiv a license to display the preprint in perpetuity. It is made available under a CC-BY-NC-ND 4.0 International license .

\section{ABNORMAL BRAIN NETWORKS OF PERCEPTUAL ORGANIZATION}

\section{Introduction}

Schizophrenia (SZ) is a debilitating disorder charactered by delusions, hallucinations, disorganized thought and a decline in social/occupational functioning. Aspects of visual perceptual organization are also compromised (Grent-'t-Jong et al., 2020; Schallmo et al., 2015; Silverstein and Keane, 2011). Here, we consider impairments in visual shape completion, which represents a partly-camouflaged shape from co-aligned step-edge elements dotting the field of view. This process is worth considering since it is important for normal seeing (Keane, 2018); its underlying mechanisms have been extensively investigated in human and non-human primates (Cox et al., 2013; Murray et al., 2006), and it has been shown to be selectively impaired in schizophrenia (Keane et al., 2019).

What causes abnormal shape completion in SZ? Foxe et al. (2005) addressed this question by monitoring visual evoked potentials as subjects discriminated configurations that formed or failed to form illusory shapes. There was an initial afferent volley of dorsal activity that was deficient in schizophrenia, an intact illusory contour formation waveform localized to lateral occipital regions (see also, Wynn et al., 2015), and increased, possibly compensatory, activity across frontal regions. In another EEG study, when subjects discriminated illusory square from non-illusory (fragmented) stimuli, schizophrenia patients exhibited a unique response-locked high-gamma oscillation $100 \mathrm{~ms}$ after button press with a fronto-central topography, implicating a later-stage disturbance (Spencer and Ghorashi, 2014). Psychophysical investigations have likewise suggested an intact illusory contour formation stage but a deficient shape integration stage, perhaps implicating object recognition structures such as orbitofrontal cortex (Keane et al., 2019). Critically, all neuroscience studies on the topic have used EEG and thus were limited in their spatial precision. A primary goal was to use multiband fMRI to identify the networks and functional connections that underlie abnormal shape completion in schizophrenia.

A second goal was to consider the neural basis of shape completion in bipolar disorder. Bipolar disorder was considered, first, because it offers an important foil for schizophrenia. Over $40 \%$ of bipolar disorder patients take anti-psychotic medications (Rhee et al., 2020), over half report at least one lifetime psychotic symptom (Dunayevich and Keck, 2000), both are associated with chronic medical problems and past substance abuse history (Cassidy et al., 2001; Dixon, 1999), and there is genetic overlap between the two (Lichtenstein et al., 2009). 
medRxiv preprint doi: https://doi.org/10.1101/2022.01.26.22269913; this version posted January 28, 2022. The copyright holder for this preprint (which was not certified by peer review) is the author/funder, who has granted medRxiv a license to display the preprint in perpetuity. It is made available under a CC-BY-NC-ND 4.0 International license .

\section{ABNORMAL BRAIN NETWORKS OF PERCEPTUAL ORGANIZATION}

Therefore, establishing group differences would more convincingly demonstrate specificity to schizophrenia. Moreover, understanding visual disturbances in bipolar disorder is important in itself. Despite being twice as prevalent as schizophrenia (American Psychiatric Association, 2013), a PubMed title/abstract search yielded 5\% as much literature on "visual perception". (Search date: October $27^{\text {th }}, 2021$ ). The few existing studies on visual integration/perceptual organization suggest intermediate deficits in bipolar disorder (Keane et al., 2021b; Schallmo et al., 2015). A final goal was to move beyond the traditional DSM-5 nosology and to probe for neural signatures that might be shared between disorders or that might depend on factors that cut across the schizo-bipolar spectrum (Kozak and Cuthbert, 2016). Based on past work, we expected to find neural signatures linked to cognitive disorganization, a cardinal symptom of schizophrenia (Keane et al., 2019; Spencer and Ghorashi, 2014; Spencer et al., 2004).

To accomplish the above objectives, we scanned participants as they discriminated pac-man configurations that either formed or failed to form visually completed shapes (illusory and fragmented condition, respectively) (Ringach and Shapley, 1996). Shape completion was operationalized as the difference in performance or activation between the two conditions. This so-called "fat/thin" task was chosen because it has been used extensively to investigate shape completion via psychophysics, fMRI, EEG, and TMS (Maertens and Pollmann, 2005; Murray et al., 2006; Pillow and Rubin, 2002; Wokke et al., 2013). A resting-state scan additionally allowed us to compute the resting-state functional connectivity (RSFC) matrix between all pairs of regions, which in turn allowed us to assess the likely utility of the functional connections for shape completion via a novel "activity flow mapping" technique (ActFlow), described further below (Cole et al., 2016).

\section{Materials and Methods}

2.1. Participants. The sample consisted of 20 healthy controls (HCs), 15 people with bipolar disorder (BPs; type I, type II, and 1 unspecified), and 16 people with schizophrenia including one with schizoaffective disorder (SZs; See Table 1). One control and one bipolar participant lacked resting-state data but were still included in the task analyses. Patients were recruited from the Newark and Piscataway outpatient and partial hospital clinics at Rutgers University Behavioral Health Care (with one exception being a schizophrenia patient from the Nathan Kline Institute in Orangeburg NY). Controls were recruited from the same metropolitan areas. 
medRxiv preprint doi: https://doi.org/10.1101/2022.01.26.22269913; this version posted January 28, 2022. The copyright holder for this preprint (which was not certified by peer review) is the author/funder, who has granted medRxiv a license to display the preprint in perpetuity. It is made available under a CC-BY-NC-ND 4.0 International license .

\section{ABNORMAL BRAIN NETWORKS OF PERCEPTUAL ORGANIZATION}

To prevent exaggerated group differences in IQ and education, controls without four-year college degrees were preferentially recruited.

Table 1. Demographic and clinical characteristics of participants

\begin{tabular}{|c|c|c|c|c|c|c|c|c|}
\hline \multirow[b]{2}{*}{ Variable } & \multicolumn{2}{|c|}{$H C(n=20)$} & \multicolumn{2}{|c|}{$B P(n=15)$} & \multicolumn{2}{|c|}{$S Z(n=16)$} & \multirow{2}{*}{$\begin{array}{c}\text { Group } \\
\text { comp. } \\
p \\
p\end{array}$} & \multirow{2}{*}{$\begin{array}{c}\text { Pairwise } \\
\text { comparisons } \\
\text { (uncorrected) }\end{array}$} \\
\hline & $\begin{array}{l}\text { Mean } \\
\text { or } \\
\text { Percent }\end{array}$ & $S D$ & $\begin{array}{l}\text { Mean } \\
\text { or } \\
\text { Percent }\end{array}$ & $S D$ & $\begin{array}{l}\text { Mean } \\
\text { or } \\
\text { Percent }\end{array}$ & $S D$ & & \\
\hline Age (yrs.) & 37.6 & 11.2 & 39.7 & 8.6 & 40.3 & 7.6 & .660 & \\
\hline $\begin{array}{c}\text { Education, } \\
\text { parental average } \\
\text { (yrs.) }\end{array}$ & 12.8 & 2.7 & 13.5 & 2.1 & 13.0 & 4.1 & .812 & \\
\hline Education, self (yrs.) & 14.9 & 2.6 & 14.6 & 1.7 & 13.0 & 3.4 & .105 & \\
\hline FSIQ (Shipley-2) & 100.5 & 9.9 & 105.7 & 5.8 & 95.6 & 14.4 & .040 & $\mathrm{SZ}<\mathrm{BP}^{*}$ \\
\hline Gender (\% Male) & 60 & & 33 & & 69 & & .118 & \\
\hline $\begin{array}{l}\text { Handedness } \\
\text { (\% Right) }\end{array}$ & 80 & & 87 & & 88 & & .515 & \\
\hline $\begin{array}{l}\text { Smoking habits } \\
\text { (\% smokers) }\end{array}$ & 17 & & 43 & & 47 & & .137 & \\
\hline $\begin{array}{l}\text { Nicotine dependence } \\
\text { (FTND scores) }\end{array}$ & 21.3 & 5.5 & 19.7 & 7.5 & 20.1 & 7.8 & .95 & \\
\hline $\begin{array}{c}\text { Antipsychotic Type: } \\
\text { typical/atypical/both } \\
(\%)\end{array}$ & & & $0 / 100 / 0$ & & $14 / 79 / 7$ & & .262 & \\
\hline $\begin{array}{l}\text { Olanzapine equiv. } \\
\text { (mg/day) }\end{array}$ & & & 6.4 & 10.6 & 14.1 & 14.5 & .103 & \\
\hline $\begin{array}{l}\text { Imipramine equiv. } \\
\text { (mg/day) }\end{array}$ & & & 41.7 & 69.9 & 31.9 & 71.8 & .703 & \\
\hline $\begin{array}{l}\text { Lithium equiv. } \\
\text { (mg/day) }\end{array}$ & & & 803.9 & 654.8 & 216.9 & 412.3 & .005 & \\
\hline $\begin{array}{c}\text { Functioning, current } \\
\text { (SLOF) }\end{array}$ & & & 4.1 & 6 & 4.1 & .5 & .736 & \\
\hline $\begin{array}{c}\text { Functioning, } \\
\text { premorbid (PAS) }\end{array}$ & & & 0.22 & 0.10 & 0.28 & 0.18 & .294 & \\
\hline Illness duration (yrs.) & & & 20.0 & 10.9 & 15.7 & 9.3 & .249 & \\
\hline $\begin{array}{c}\text { Illness onset age } \\
\text { (yrs.) }\end{array}$ & & & 19.6 & 9.5 & 22.3 & 9.2 & .458 & \\
\hline CDSS, total & & & 6.9 & 6.3 & 4.7 & 3.6 & .250 & \\
\hline $\begin{array}{c}\text { Schizo-Bipolar Scale, } \\
\text { total }\end{array}$ & & & 1.7 & 1.8 & 7.6 & 1.5 & $<.001$ & \\
\hline YMRS, total & & & 2.9 & 2.6 & 9.1 & 6.6 & .002 & \\
\hline
\end{tabular}


medRxiv preprint doi: https://doi.org/10.1101/2022.01.26.22269913; this version posted January 28, 2022. The copyright holder for this preprint (which was not certified by peer review) is the author/funder, who has granted medRxiv a license to display the preprint in perpetuity. It is made available under a CC-BY-NC-ND 4.0 International license .

ABNORMAL BRAIN NETWORKS OF PERCEPTUAL ORGANIZATION

\begin{tabular}{|c|c|c|c|c|c|}
\hline PANSS, positive & 1.4 & 0.6 & 2.8 & 1.1 & $<.001$ \\
\hline PANSS, negative & 1.6 & 0.7 & 1.8 & 0.6 & .318 \\
\hline PANSS, disorganized & 1.8 & 0.4 & 2.3 & 0.8 & .045 \\
\hline PANSS, excitement & 1.7 & 0.5 & 1.8 & 0.5 & .498 \\
\hline PANSS, depression & 3.5 & 1.5 & 3.2 & 1.1 & .586 \\
\hline PANSS, total & 1.7 & 0.4 & 2.2 & 0.4 & .001 \\
\hline
\end{tabular}

Note. $\mathrm{FSIQ}=$ Full-Scale IQ. SLOF = Specific Levels of Functioning Scale mean score per scorable item (1-5, with 5 being highest functioning). FTND =Faegerstrom Test of Nicotine Dependence, which were only reported for subjects who smoked. Antipsychotic type pertains only to those who were using antipsychotics. PAS = Premorbid Adjustment Scale, averaged across age period (with higher scores denoting more dysfunction). CDSS = Calgary Depression Scale for Schizophrenia. YMRS = Young Mania Rating Scale. PANSS = Positive and Negative Syndrome Scale mean score per item. Interval/ordinal variables were compared with ANOVAs/t-tests. Frequency statistics (e.g., handedness) were measured with Chi-square or Fisher's exact test (i.e., on $2 \times 2$ tables). ${ }^{*} \mathrm{p}<.05$ uncorrected.

The inclusion/exclusion criteria for all subjects were: (1) age 21-55; (2) no electroconvulsive therapy in the past 8 weeks; (3) no neurological or pervasive developmental disorders; (4) no recent substance use disorder (i.e., participants must not have satisfied more than one of the 11 Criterion A symptoms of DSM-5 substance use disorder in the last three months); (5) no positive urine toxicology screen or breathalyzer test on any day of testing, including THC; (6) no brain injury due to accident or illness (e.g., stroke or brain tumor) and no accompanying loss of consciousness for more than 10 minutes; (7) no amblyopia (as assessed by informal observation and self-report); (8) visual acuity of 20/32 or better (with corrective lenses if necessary); (9) the ability to understand English and provide written informed consent; (10) no scanner related contraindications (no claustrophobia, an ability to fit within the scanner bed, and no non-removable ferromagnetic material on or within the body); 11) no intellectual impairment $(\mathrm{IQ}<70)$ as assessed with brief vocabulary test (Shipley-2; see below). Additional criteria for controls were: (1) no DSM-5 diagnosis of past or current psychotic or mood disorders (including past mood episode); (2) no current psychotropic- or cognition-enhancing medication; (3) no first-degree relative with schizophrenia, schizoaffective, or bipolar disorder (as indicated by self-report). Additional criteria for patients were: (1) a DSM-5 diagnosis of schizophrenia, schizoaffective (depressive subtype), or bipolar disorder. Patients could not be in a manic state at the time of testing.

The participants in our study-while less numerous-were well-vetted and highly functioning, with few comorbidities. Of the consented HCs, 6 met DSM-5 criteria for an 
medRxiv preprint doi: https://doi.org/10.1101/2022.01.26.22269913; this version posted January 28, 2022. The copyright holder for this preprint (which was not certified by peer review) is the author/funder, who has granted medRxiv a license to display the preprint in perpetuity. It is made available under a CC-BY-NC-ND 4.0 International license .

\section{ABNORMAL BRAIN NETWORKS OF PERCEPTUAL ORGANIZATION}

undisclosed past or current mood disorder (typically major depressive disorder), 1 could not reach a visual acuity of 20/32, 1 had amblyopia, 1 had scanner related contraindications, 4 tested positive for recreational or illicit substances, and 1 was excluded due to a safety concern. Of the consented BPs, 3 were excluded due to age (verified with ID), 6 had an IQ < 70, 2 could not reach a visual acuity of 20/32, 1 was excluded due to a head injury, 1 had scanner related contraindications, 1 had an alcohol use disorder, 2 tested positive for recreational or illicit substances, 1 had a neurological disorder, and 4 were excluded for multiple reasons. Of the consented SZs, 11 had an $I Q<70,1$ had amblyopia, 1 had scanner related contraindications, 2 had alcohol use disorders, 4 tested positive for recreational or illicit substances, and 2 were excluded for multiple reasons. The foregoing exclusions were in addition to those who were screened out before the consent, who ultimately received an inappropriate diagnosis, or who were disqualified for exhibiting COVID-19 symptoms or who had comorbidities that exacerbated the risks of COVID-19 (in the last year of recruitment).

Written informed consent was obtained from all subjects after explanation of the nature and possible consequences of participation. The study followed the tenets of the Declaration of Helsinki and was approved by the Rutgers University Institutional Review Board. All participants received monetary compensation and were naive to the study's objectives.

\subsection{Assessments.}

Psychiatric diagnosis was assessed with the Structured Clinical Interview for DSM-5 (28) and was assigned only after consulting detailed medical history and the SCID. All diagnoses were further considered during a weekly diagnostic consensus meeting. All clinical instruments were administered by a rater who had established reliability with raters in other ongoing studies (ICC > 0.8).

Intellectual functioning of all subjects was assessed with a brief vocabulary test that correlates highly ( $r=0.80$ ) with WAIS-III full-scale IQ scores (Canivez and Watkins, 2010; W. C. Shipley et al., 2009, p. 65). Visual acuity was measured with a logarithmic visual acuity chart under fluorescent overhead lighting (viewing distance $=2$ meters, lower limit =20/10), and inhouse visual acuity correction was used for individuals without appropriate glasses or contacts. The Alere iCup Dx Drug Screen Cup was utilized to probe for the presence of recreational and illicit substances (i.e., THC, cocaine, methamphetamines, amphetamines, and opiates). The 
medRxiv preprint doi: https://doi.org/10.1101/2022.01.26.22269913; this version posted January 28, 2022. The copyright holder for this preprint (which was not certified by peer review) is the author/funder, who has granted medRxiv a license to display the preprint in perpetuity. It is made available under a CC-BY-NC-ND 4.0 International license .

\section{ABNORMAL BRAIN NETWORKS OF PERCEPTUAL ORGANIZATION}

AlcoHawk Pro breathalyzer was administered to test for recent alcohol consumption. All included subjects tested negative for each test at the time of scanning. Nicotine use was assayed with the Faegerstrom Test for Nicotine Dependence (FTND) (Heatherton et al., 1991). Standardized medication dose equivalents (olanzapine, lithium, and imipramine equivalents) were determined for each patient using published tables (Bollini et al., 1999; Gardner et al., 2010) (Table 1).

The Positive and Negative Syndrome Scale (PANSS; Kay et al., 1987) was administered within two weeks of the scan and provided information about symptoms over the last two weeks. PANSS symptom scores were reported via a "consensus" 5-factor model, which was designed on the basis of 29 previous five-factor models (Wallwork et al., 2012). The disorganization score was the clinical variable of greatest interest, given its relation to shape completion (Keane et al., 2019).

To fully characterize the patient samples, we also administered several other symptom/functioning assessments. Depressive and manic symptoms were assessed with the Calgary Depression Scale in Schizophrenia (D. Addington et al., 1993) and the Young Mania Rating Scale, respectively (Young et al., 1978). The Specific Levels of Functioning Scale (SLOF) estimated day-to-day functioning in areas such as physical functioning, personal care, interpersonal relationships, social acceptability, activities, and work skills. The Premorbid Adjustment Scale (PAS; Cannon-Spoor et al., 1982) measured sociability, peer relationship quality, scholastic performance, school adaptation, and (where appropriate) social-sexual functioning up to 1 year before illness onset; this was done for childhood (up through age 11), early adolescence (ages 12-15), late adolescence (ages 16-18), and adulthood (ages 19 and above). In line with what others have done, the PAS General score was not included since it is reflective of functioning before and after illness onset (van Mastrigt and J. Addington, 2002). For individuals with schizophrenia, illness onset on the PAS was defined as when one or more positive symptoms first became noticeable or concerning to the patient. For individuals with bipolar disorder, illness onset was defined as the onset of the first mood episode (either manic or major depressive). Each patient's position along the schizo-bipolar spectrum was assessed with the Schizo-Bipolar Scale (Keshavan et al., 2011). Higher scores indicated that a subject was more toward the pure 'schizophrenia' end of the spectrum. 
medRxiv preprint doi: https://doi.org/10.1101/2022.01.26.22269913; this version posted January 28, 2022. The copyright holder for this preprint (which was not certified by peer review) is the author/funder, who has granted medRxiv a license to display the preprint in perpetuity. It is made available under a CC-BY-NC-ND 4.0 International license .

ABNORMAL BRAIN NETWORKS OF PERCEPTUAL ORGANIZATION

\subsection{Experimental Design and Statistical Analysis}

\subsubsection{Stimulus and procedure.}

Participants performed a "fat/thin" shape discrimination task in which they indicated whether four pac-men formed a fat or thin shape ("illusory" condition) or whether four downward-facing pac-men were uniformly rotated left or right ("fragmented" condition) (see Fig. 1). The fragmented task is a suitable control in that it involves judging the lateral properties of the stimulus-just like the illusory condition-and in that it uses groupable elements (via common orientation, Beck, 1966). As described elsewhere (Keane et al., 2021), the two tasks shared most stimulus and procedural details (stimulus timing, pac-man features, spatial distribution, etc.) and therefore relied on many of the same processes (temporal attention, divided attention, visual working memory, etc.) (Keane et al., 2019). Perhaps because of these similarities, the tasks generate similar performance thresholds, reaction times, and accuracies, and are highly correlated behaviorally (Keane et al., 2019; 2021a), which is interesting since extremely similar visual tasks are often uncorrelated even within large samples (Grzeczkowski et al., 2017). In sum, by having employed a closely matched and already tested control condition, we were in a position to judge mechanisms relatively unique to shape completion.

Subjects viewed the stimuli in the scanner from a distance of $99 \mathrm{~cm}$ by way of a mirror attached to the head coil. There were four white sectored circles (radius $=.88 \mathrm{deg}$, or 60 pixels) centered at the vertices of an invisible square (side $=5.3 \mathrm{deg}$, or 360 pixels), which itself was centered on a gray screen (see Figure 3). Stimuli were initially generated with MATLAB and Psychtoolbox code (Pelli, 1997) with anti-aliasing applied for edge artifact removal. Images were subsequently presented in the scanner via PsychoPy (version 1.84; (Peirce, 2007) on a MacBook Pro. Illusory contour formation depended on the geometric property of "relatability" (Kellman and T. Shipley, 1991): when the pac-men were properly aligned (relatable), the illusory contours were present (the "illusory" condition); when misaligned (unrelatable), they were absent ("fragmented" condition). 
medRxiv preprint doi: https://doi.org/10.1101/2022.01.26.22269913; this version posted January 28, 2022. The copyright holder for this preprint (which was not certified by peer review) is the author/funder, who has granted medRxiv a license to display the preprint in perpetuity. It is made available under a CC-BY-NC-ND 4.0 International license .

\section{ABNORMAL BRAIN NETWORKS OF PERCEPTUAL ORGANIZATION}

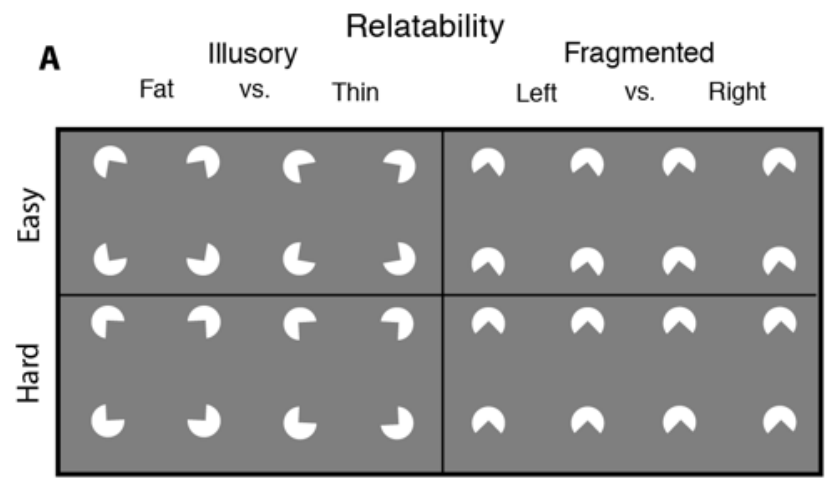

B

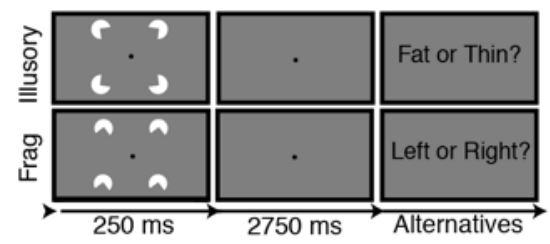

C

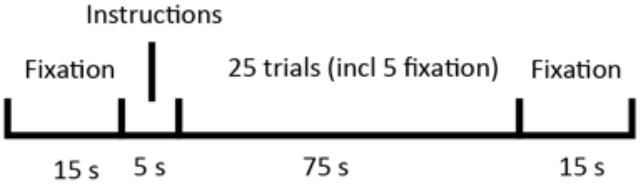

Fig. 1. Stimuli, trial sequence, and block arrangement for the visual shape completion experiment. (A) Sectored circles (pac-men) were oriented to generate visually completed shapes (illusory condition) or fragmented configurations that lacked interpolated boundaries (fragmented condition). There were two difficulty conditions corresponding to the amount by which the pac-men were individually rotated to create the response alternatives. (B) After briefly seeing the target, subjects responded with a button press. (C) Each half of a run consisted of a fixation screen, a 5 second instructional screen, 25 trials of a single task condition (including 5 fixation trials), and then another fixation screen. Figure re-used from (Keane et al., 2021a).

Within each of the four runs, there was one block of each task condition. Block ordering (illusory/fragmented or vice versa) alternated from one run to the next. Each block had two difficulty levels, corresponding to the magnitude of pac-man rotation (+/- 10 degrees "easy", or +/- 3 degrees of rotation, "hard"). Within each block, there were 20 task trials and 5 fixation trials. Half of the task trials were easy, and half were hard; half of these two trial types were illusory, and half were fragmented. The ordering of these trial types (including fixation) was counterbalanced. Each trial consisted of a $250 \mathrm{~ms}$ pac-man stimulus (task trial) or $250 \mathrm{~ms}$ fixation dot (fixation trial), followed by a $2750 \mathrm{~ms}$ fixation dot. Subjects needed to issue a response before the end of a task trial; otherwise, a randomly selected response was assigned 
medRxiv preprint doi: https://doi.org/10.1101/2022.01.26.22269913; this version posted January 28, 2022. The copyright holder for this preprint (which was not certified by peer review) is the author/funder, who has granted medRxiv a license to display the preprint in perpetuity. It is made available under a CC-BY-NC-ND 4.0 International license .

\section{ABNORMAL BRAIN NETWORKS OF PERCEPTUAL ORGANIZATION}

at the end of that trial and the following trial ensued. Feedback was provided at the end of each run in the form of accuracy averaged cumulatively across all test trials.

Subjects received brief practice outside of and within the scanner before the actual experiment. During practice, subjects were reminded orally and in writing to keep focused on a centrally-appearing fixation point for each trial. To ensure that subjects thoroughly understood the task, pictures of the fat/thin stimuli were shown side-by-side and in alternation so that the differences could be clearly envisaged. Subjects issued responses with a twobutton response device that was held on their abdomens with their dominant hand. Subjects practiced with this same type of device outside of the scanner. Feedback after each trial was provided during the practice phase only (correct, incorrect, slow response).

\subsection{2. $\mathrm{fMRI}$ acquisition}

Data were collected at the Rutgers University Brain Imaging Center (RUBIC) on a Siemens Tim Trio scanner. Whole-brain multiband echo-planar imaging (EPI) acquisitions were collected with a 32-channel head coil with TR $=785 \mathrm{~ms}$, TE $=34.8 \mathrm{~ms}$, flip angle $=55^{\circ}$, bandwidth 1894/Hz/Px, in-plane FoV read = $211 \mathrm{~mm}, 60$ slices, $2.4 \mathrm{~mm}$ isotropic voxels, with GRAPPA (PAT=2) and multiband acceleration factor 6. Whole-brain high-resolution T1weighted and T2-weighted anatomical scans were also collected with $0.8 \mathrm{~mm}$ isotropic voxels. Spin echo field maps were collected in both the anterior-to-posterior and posterior-to-anterior directions in accordance with the Human Connectome Project preprocessing pipeline (version 3.25.1) (Glasser et al., 2013). After excluding dummy volumes to allow for steady-state magnetization, each experimental functional scan spanned $3 \mathrm{~min}$ and $41 \mathrm{~s}$ (281 TRs). Scans were collected consecutively with short breaks in between (subjects did not leave the scanner). An additional 10-minute resting-state scan (765 TRs) occurred in a separate session, with the same pulse sequence. Note that due to scanner time constraints one SZ participant finished only 751 of the 765 TRs.

\subsection{3. $\mathrm{fMRI}$ preprocessing and functional network partition}

Preprocessing steps have been reported before (Keane et al., 2021a) but are repeated below. Imaging data were preprocessed using the publicly available Human Connectome Project minimal preprocessing pipeline which included anatomical reconstruction and segmentation; and EPI reconstruction, segmentation, spatial normalization to standard template, intensity normalization, and motion correction (Glasser et al., 2013). All subsequent preprocessing 
medRxiv preprint doi: https://doi.org/10.1101/2022.01.26.22269913; this version posted January 28, 2022. The copyright holder for this preprint (which was not certified by peer review) is the author/funder, who has granted medRxiv a license to display the preprint in perpetuity. It is made available under a CC-BY-NC-ND 4.0 International license .

\section{ABNORMAL BRAIN NETWORKS OF PERCEPTUAL ORGANIZATION}

steps and analyses were conducted on CIFTI 64k grayordinate standard space. This was done for the parcellated time series using the Glasser et al. (2016) atlas (i.e., one BOLD time series for each of the 360 cortical parcels, where each parcel averaged over vertices). The Glasser surface-based cortical parcellation combined multiple neuroimaging modalities (i.e., myelin mapping, cortical thickness, task $\mathrm{fMRI}$, and RSFC) to improve confidence in cortical area assignment. The parcellation thus provided a principled way to parse the cortex into manageable number of functionally meaningful units and thereby reduce the number of statistical comparisons. The parcellation also provided units for the brain network partition described further below.

We performed nuisance regression on the minimally preprocessed task data using 24 motion parameters (6 motion parameter estimates, their derivatives, and the squares of each) and the 4 ventricle and 4 white matter parameters (parameter estimates, the derivates, and the squares of each) (Ciric et al., 2017). For the task scans, global signal regression, motion scrubbing, spatial smoothing, and temporal filtering were not used. Each run was individually demeaned and detrended ( 2 additional regressors per run).

The resting-state scans were preprocessed in the same way as the parcellated task data (including the absence of global signal regression) except that we removed the first five frames and applied motion scrubbing (Power et al., 2012). That is, whenever the framewise displacement for a particular frame exceeded $0.3 \mathrm{~mm}$, we removed that frame, one prior frame, and two subsequent frames (Schultz et al., 2018). Framewise displacement was calculated as the Euclidean distance of the head position in one frame as compared to the one preceding. One HC and one BP did not perform a resting-state scan; one SZ and one BP had too few frames after motion scrubbing ( $<2.5$ standard deviations relative to the mean of their respective subject groups). Group comparisons on the remaining subjects (19 HCs, 15 SZs, and $13 \mathrm{BPs}$ ) revealed no differences on either the mean framewise displacement after motion scrubbing $\left(\mathrm{M}_{\mathrm{HC}}=.12, \mathrm{M}_{\mathrm{BP}}=.15\right.$, and $\left.\mathrm{M}_{\mathrm{SZ}}=.14 \mathrm{~mm} ; \mathrm{F}(2,44)=1.49, \mathrm{p}=.23\right)$ or the mean number of unscrubbed frames $(\mathrm{HC}-696, \mathrm{BP}-632, \mathrm{SZ}-663 ; \mathrm{F}(2,44)=1.59, \mathrm{p}=.22)$.

For the task scans, there were 6 task regressors, one for each instructional screen (illusory/fragmented) and one for each of the four trial types (illusory/fragmented, easy/hard). A standard fMRI general linear model (GLM) was fit to task-evoked activity convolved with the SPM canonical hemodynamic response function (using the function spm_hrf.m). Betas for the 
medRxiv preprint doi: https://doi.org/10.1101/2022.01.26.22269913; this version posted January 28, 2022. The copyright holder for this preprint (which was not certified by peer review) is the author/funder, who has granted medRxiv a license to display the preprint in perpetuity. It is made available under a CC-BY-NC-ND 4.0 International license .

\section{ABNORMAL BRAIN NETWORKS OF PERCEPTUAL ORGANIZATION}

illusory and fragmented condition were derived from all trials of the relevant condition across all four runs. For the within-group classifier analyses, described below, task activation betas were derived separately for each run, but all other steps were the same as described.

The location and role of each parcel was considered within the context of their functional network affiliations. An advantage of network-based analyses (rather than individual clusters) is that it substantially increases power to detect average-size effects (Noble et al., 2021). We used the Cole-Anticevic Brain Network partition, which comprised 12 functional networks that were constructed from the above-mentioned parcels and that were defined via a General Louvain community detection algorithm using resting-state data from 337 healthy adults (Ji et al., 2019 see Figure 4A). This partition included: well-known sensory networksprimary visual, secondary visual, auditory, somatosensory; previously identified cognitive networks-frontoparietal, dorsal attention, cingulo-opercular, and default mode; a leftlateralized language network; and three entirely novel networks-posterior multimodal, ventral multimodal, and orbito-affective. In addition to these 12 functional networks, we also considered what we dub the "visual shape completion network coalition" or more simply the "shape completion network". This consisted of 36 significantly modulated parcels that were previously reported from our healthy control sample (where "modulations" refer to illusoryfragmented differences) (Keane et al., 2021). As shown further below, this network was relevant to shape completion in each of the three subject groups, albeit in different ways.

\subsubsection{Univariate task activation analyses and follow-up tests on heterogeneity}

For the univariate task activation analyses, betas for each subject were derived for each parcel, averaged across difficulty condition, and subtracted (illusory-fragmented). These values were then compared to zero across subjects with a one-sample t-test. To be consistent with previous work on healthy controls (Keane et al., 2021a), we designated eight parcels of a priori interest in each hemisphere for the task activation analysis. These ROls have been assigned different names across different research studies (shown in parentheses) and are as follows: V1 (17, hOC1, OC, BA17), V2 (18, hOC2, OB, BA18), V4 (V4d, V4v, hV4, hOC4v, hOC4lp), V4t (LO2), LO1 (LO2, hOC4la); LO2 (LO1, hOC4la), LO3 (hOC4la), and V3CD (V3A,V3B, hOC4la) (Glasser et al., 2016, p. 81 see of Supplementary Neuroanatomical Results). Note that V3CD was included because it corresponds to the anterior third of the 
medRxiv preprint doi: https://doi.org/10.1101/2022.01.26.22269913; this version posted January 28, 2022. The copyright holder for this preprint (which was not certified by peer review) is the author/funder, who has granted medRxiv a license to display the preprint in perpetuity. It is made available under a CC-BY-NC-ND 4.0 International license .

\section{ABNORMAL BRAIN NETWORKS OF PERCEPTUAL ORGANIZATION}

middle and inferior lateral occipital gyri (area hOc4la as labeled by Malikovic et al., 2016). As in our past work, regions that were and were not of a priori interest were separately corrected for multiple comparisons via the False Discovery Rate (FDR) method (Benjamini and Hochberg, 1995).

To further understand the group-averaged results (with patient groups yielding fewer significant regions), we ran the same univariate task activation analysis as just described at the individual subject level, using each subject's estimated covariance matrix, task betas, and MATLAB's linear hypothesis test function (linhyptest). Regions that were and were not of a priori interest were separately corrected for multiple comparisons as before.

As a more direct confirmation that patients' weak group-averaged univariate results arose from heterogeneity, we correlated each subject's parcel-wise vector of illusoryfragmented modulations with the average modulations from the remaining subjects, and then compared these correlation values (after Z-transforming) between groups with independent sample t-tests.

\subsubsection{Multivariate pattern analyses}

To understand whether specific networks were being used within each subject, we performed a MVPA with an exhaustive leave-two-runs-out cross-validation for each network (equivalent to split-half cross-validation). This previously used procedure (Keane et al., 2021a) entailed determining whether the parcel-wise betas for each of the two left-out runs better correlated to the averaged illusory or fragmented betas of the remaining runs, keeping in mind that the number of illusory/fragmented trials was the same in each run. Similar to past studies, we chose Pearson correlation as the minimum distance classifier (Mill et al., 2020; Mur et al., 2009; Spronk et al., 2020) because it intuitively measures a group's proximity to an individual in multivariate feature space without requiring parameter choices (e.g., the " $\mathrm{C}$ " parameter in support vector machines). Note also that simple linear classifiers perform just as well as sophisticated non-linear methods (e.g., deep learning) with noisy (fMRI) data (Schulz et al., 2020). Results were averaged for each subject across the 6 possible ways to divide the four runs between test and validation. Statistical significance was determined via permutation tests, which generated a null distribution of classification accuracies through the same procedure with 10,000 samples. That is, for each sample and before the cross-validation, the "illusory" 
medRxiv preprint doi: https://doi.org/10.1101/2022.01.26.22269913; this version posted January 28, 2022. The copyright holder for this preprint (which was not certified by peer review) is the author/funder, who has granted medRxiv a license to display the preprint in perpetuity. It is made available under a CC-BY-NC-ND 4.0 International license .

\section{ABNORMAL BRAIN NETWORKS OF PERCEPTUAL ORGANIZATION}

and "fragmented" labels were shuffled for each subject and run. The classification results were then averaged across subjects and across the 6 possible divisions of test and validation data sets. FDR correction was applied to the 13 tests (twelve resting-state networks plus the shape completion network).

To determine which networks were differentially modulated between groups, we conducted, for each pair of groups, a repeated split-half cross-validation using illusory/fragmented activation differences as features. More explicitly, for each repetition of the cross-validation, we considered whether the parcel-wise activation differences (illusoryfragmented) for half of the subjects better correlated with the averaged activation differences of the remaining subjects of each of the two subject groups. Folds were stratified to ensure that each was representative of the overall sample. Results were averaged over 20 repetitions, by which point statistical power plausibly reaches a near-maximum (Valente et al., 2021). Accuracy, sensitivity, specificity, and areas under the curve were calculated using classification values that were averaged across repetitions for each subject. The classifier's statistical significance was judged relative to a null distribution, which was created by shuffling the subject group labels and repeating the foregoing steps for each of 10,000 samples. Note that the labels were permuted outside of the cross-validation loops, which gives less optimistic (and more realistic) estimates of the underlying null (Etzel and Braver, 2013; Valente et al., 2021). Note also that for each group comparison and across all networks, the mean value of the null distribution always fell near 50\% accuracy (range: 49.9-51.2\%), demonstrating that sample size imbalances introduced minimal classifier bias. MVPA was applied to each of the twelve resting-state networks plus the shape completion network. Resulting p-values were FDR corrected as before.

\subsubsection{Estimating and comparing resting-state functional connectivity matrices}

We generated a resting-state functional connectivity (RSFC) matrix for each subject to assess how the shape completion network might be differently configured in each group and to model group differences in shape completion via ActFlow (see below). We derived each subject's RSFC by using principal components regression with 100 components, as in past studies (Hearne et al., 2021; Keane et al., 2021a). PC regression was preferred over ordinary least squares to prevent over-fitting (using all components would inevitably capture noise in the 
medRxiv preprint doi: https://doi.org/10.1101/2022.01.26.22269913; this version posted January 28, 2022. The copyright holder for this preprint (which was not certified by peer review) is the author/funder, who has granted medRxiv a license to display the preprint in perpetuity. It is made available under a CC-BY-NC-ND 4.0 International license .

\section{ABNORMAL BRAIN NETWORKS OF PERCEPTUAL ORGANIZATION}

data). Multiple regression was preferred over Pearson correlation since the former removes indirect connections (Reid et al., 2019). For example, if there exists a true connection from $A$ to $\mathrm{B}$ and $\mathrm{B}$ to $\mathrm{C}$, a Pearson correlation, but not regression, would incorrectly show connections between $A$ and $C$. To generate a subject's RSFC, for each target parcel time series, we used PCA to decompose the time series of the remaining $(\mathrm{N}=359)$ parcels into 100 components, regressed the target onto the PCA scores, and back-transformed the PCA betas into a parcelwise vector. The average amount of variance explained by the components across subjects was $84 \%$ for controls [range: $81-88 \%$ ], $84 \%$ for bipolar patients, [range: $78-89 \%$ ] and $83 \%$ for schizophrenia patients [range: 81-85\%]

Group differences/similarities in RSFC were assessed in four ways. First, we compared groups on the integrity of the shape completion network by calculating the within- versus between network connection weight for each group (paired t-tests) (Keane et al., 2021a) and comparing these differences between groups (independent samples t-test). Next, we compared groups on each connection weight in the $36 \times 36$ restricted RSFC matrix and in the full 360x360 matrix using FDR-corrected independent t-tests. Third, we considered whether patterns of connection weights differed between groups, by vectorizing the lower triangle of each subject's RSFC matrix and employing the between-group MVPA method described above. This was done for the shape completion network and, for completeness, all 12 restingstate networks, FDR-correcting the effects as before. Finally, we quantified the similarity between FC matrices via the non-parametric Mantel permutation test (Mantel, 1967; Spronk et al., 2020), which accounts for the non-independence of FC matrix values. This test was conducted by i) taking the lower triangle of the RSFC matrices of each subject, ii) averaging the vectorized regression weights element wise across subjects within group, and iii) computing a Pearson's R between the two group-averaged vectors. Statistical significance of the resulting correlation was judged relative to a null distribution, which was generated the same way except that the region identities were shuffled for each of 10,000 samples. As in prior work, the resulting null distribution for this RSFC analysis was converted into a probability distribution function (using MATLAB function ksdensity) before calculating a p-value (Spronk et al., 2020).

\subsubsection{Brain activity flow mapping (“ActFlow”)}


medRxiv preprint doi: https://doi.org/10.1101/2022.01.26.22269913; this version posted January 28, 2022. The copyright holder for this preprint (which was not certified by peer review) is the author/funder, who has granted medRxiv a license to display the preprint in perpetuity. It is made available under a CC-BY-NC-ND 4.0 International license .

\section{ABNORMAL BRAIN NETWORKS OF PERCEPTUAL ORGANIZATION}

In the next set of analyses, we employed brain activity flow mapping ("ActFlow) to model illusory/fragmented task activation differences with resting-state data. For each subject, task activations in a held-out parcel ('j' in Fig. 5A) was predicted as the weighted average of the activations of all other parcels, with the weights being given by the resting-state connections. That is, for each subject, each held-out region's predicted value was given as the dot product of the task activations in the remaining regions ('i' in Fig. 5A) and the subject's restFC between $\mathrm{j}$ and $\mathrm{i}$ (using the FC weight from the appropriately oriented regression, i.e., $\mathrm{j}$ as the target and $\mathrm{i}$ as the predictor). The accuracy of the activity flow predictions was then assessed by computing the overlap (Pearson correlation) between the predicted and actual task activations. Subject-level overlap was expressed by comparing actual and predicted activations for each subject, and then averaging the resulting Fisher-transformed $r$ values $\left(r_{z}\right)$ across subjects (subject-level overlap). Statistical significance was determined by comparing the vector of $r_{z}$ values to zero via a one-sample t-test. Group-level overlap was expressed by averaging the predicted values across subjects and then comparing that to the averaged actual values, which will yield a single Pearson $r$ value. ActFlow has yielded accurate estimates of task-evoked activations for tasks of cognitive control, visual working memory, and visual shape completion, among others (Cole et al., 2016; Hearne et al., 2021; Keane et al., 2021a).

Brain activity flow mapping offered several insights. First, if a given RSFC matrix can be used to predict task activation differences in a subject group, then that would show that those same functional connections likely contribute to task performance. This in turn would license inferences about which connections, if any, contribute to abnormal task modulations in patients. Second, in a post-hoc analysis complementary to the univariate analysis above, we used ActFlow to quantify inter-subject variability. Group-level estimates exceed subject-level estimates partly because subjects neurally represent stimuli in similar ways and averaging across subjects will reduce noise in the analysis (Cole et al., 2016). While other factors can inflate the group-level ActFlow estimate (spatial misalignment between subjects), all else equal, if the difference between these estimates is smaller for one group, then that suggests that there is more heterogeneity in that group. Finally, we applied the ActFlow methodology to consider possible group differences in how other networks interface with the secondary visual network. The secondary visual network was of interest because it is central to shape completion in healthy adults (Keane et al., 2021a) and because particular regions falling within 
medRxiv preprint doi: https://doi.org/10.1101/2022.01.26.22269913; this version posted January 28, 2022. The copyright holder for this preprint (which was not certified by peer review) is the author/funder, who has granted medRxiv a license to display the preprint in perpetuity. It is made available under a CC-BY-NC-ND 4.0 International license .

\section{ABNORMAL BRAIN NETWORKS OF PERCEPTUAL ORGANIZATION}

this network (i.e., LO, V4) have been repeatedly implicated in shape completion via EEG, MEG, TMS, and single-unit recording (Cox et al., 2013; Halgren et al., 2003; Murray et al., 2006; Wokke et al., 2013). We considered how ActFlow estimates improved in that network, when any of the remaining networks were individually added (Fig. 6). This change was determined simply by comparing via a paired t-test the prediction accuracies (Fisher Ztransformed correlations) before and after adding each network. A significant improvement would indicate which other networks, if any, guided activity flow in the secondary visual network. To show that our results also apply specifically to the shape completion network, we additionally ran the foregoing analysis only with its constituent 36 regions.

\subsubsection{Predicting cognitive disorganization from illusory/fragmented parcel-wise modulations}

The dorsal attention network was differentially modulated in SZs relative to the other groups in the aforementioned MVPA. Cognitive disorganization has been associated with impaired shape completion and altered neural oscillations as noted (Keane et al., 2019; Spencer et al., 2004; Spencer and Ghorashi, 2014). To consider whether symptoms could be predicated by dorsal attention modulations, we ran a linear regression with leave-one-out cross-validation. Leave-one-out was chosen because, contrary to popular conceptions, it generally yields the least bias/variance for prediction (Y. Zhang and Yang, 2015) and because its predictions can generalize surprisingly well to held-out fMRI data (Anticevic et al., 2014; Rosenberg et al., 2015). Within each training loop, the outcome variable (disorganization) and each predictor variable (modulations for a given DAN parcel) were z-scored using the means and standard deviations from the training set (to prevent circularity) (Mill et al., 2020; Shen et al., 2017). In the training set, the disorganization scores were regressed onto the modulations and the resulting beta coefficients were used to predict the held-out subject's disorganization score. Model prediction accuracy was gauged as the mean absolute error between predicted and actual disorganization (MAE). Statistical significance was judged via permutation testing. That is, we compared the true MAE to a distribution of such values that were generated by randomly shuffling the disorganization scores across subjects (without changing the feature matrix). As before, the disorganization variable was reshuffled once for each of the 10,000 samples of the null distribution, before the cross-validation loops. To demonstrate robustness, we additionally ran repeated leave-two-out and 10-fold cross-validation. The method was the 
medRxiv preprint doi: https://doi.org/10.1101/2022.01.26.22269913; this version posted January 28, 2022. The copyright holder for this preprint (which was not certified by peer review) is the author/funder, who has granted medRxiv a license to display the preprint in perpetuity. It is made available under a CC-BY-NC-ND 4.0 International license .

\section{ABNORMAL BRAIN NETWORKS OF PERCEPTUAL ORGANIZATION}

same as just described except that MAE was averaged across 100 randomized splits between test and training.

\subsubsection{Experimental design and statistical analysis}

Analyses were performed with RStudio (Version 1.2.1335) and MATLAB R2019a, except for the behavioral analyses which were done with SPSS version 27 . Cortical visualizations were created with Workbench (version 1.2.3). Between-group variance was removed from error bars when reporting the standard error of the means in within-subject comparisons (Loftus, 1994). The final sample sizes were determined by the duration of the NIH grant (see Acknowledgements and section 2.1 above). FDR correction, when applied, was denoted by $\mathrm{p}_{\text {corr }}$ and had a threshold of $\mathrm{q}<.05$. T-test effect sizes were given as Hedges' $\mathrm{g}$ and were generated with the measures-of-effect-size toolbox in Matlab (Hentschke, 2021).

\subsubsection{Data/code accessibility}

Brain activity flow mapping Matlab code is part of the freely-available ActFlow toolbox: https://github.com/ColeLab/ActflowToolbox. HCP minimal preprocessing pipelines are also publicly available: https://github.com/Washington-University/HCPpipelines/releases. The Cole Anticevic Brain Network partition can be found here:

https://github.com/ColeLab/ColeAnticevicNetPartition. Neural data will be released on OpenNeuro.org along with resting-state functional connectivity matrices and unthresholded task activation maps.

\section{Results}

In this section, we report behavioral results and then employ univariate/multivariate analyses to determine how each group may have relied upon each network during shape completion. Next, we computed-and compared groups on-the resting-state functional connectomes (RSFC matrices), with special consideration given to the shape completion network. Third, in each subject group, we harnessed ActFlow to demonstrate the likely utility of these functional connections for shape completion. Fourth, again using ActFlow, we built off of past work and determined for each group which network could improve the modeling estimates of shape completion modulations in the secondary visual network (whose relevance was established in 
medRxiv preprint doi: https://doi.org/10.1101/2022.01.26.22269913; this version posted January 28, 2022. The copyright holder for this preprint (which was not certified by peer review) is the author/funder, who has granted medRxiv a license to display the preprint in perpetuity. It is made available under a CC-BY-NC-ND 4.0 International license .

\section{ABNORMAL BRAIN NETWORKS OF PERCEPTUAL ORGANIZATION}

past work (e.g., Keane et al., 2021a) (Fig. 6). Fifth, we demonstrate that activations in the dorsal attention network could transdiagnostically predict cognitive disorganization severity. The foregoing analyses, taken collectively, establish clinically relevant differences in the dorsal attention network in schizophrenia; they also show more heterogeneous and more distributed shape representations in both patient groups. In the Discussion, we argue from past studies that the dorsal attention network in schizophrenia may be both deficient and compensatory: that is, it may fail to adequately send attention-based feedback to the secondary visual network, yet it may compensate by performing computations that would ordinarily be handled by vision or by coordinating with other non-visual networks.

\subsection{Behavioral task performance}

Employing a 2 (task condition) by 2 (difficulty) by 3 (group) within-subjects ANOVA (type III sum of squares), we found that performance was more accurate in the fragmented than illusory condition ( $88.9 \%$ versus $80.9 \%, F(1,48)=28.9, p<.01)$ and better in the ("easy") largerotation condition than the "hard" small-rotation condition $\left(F(1,48)=229.5, p<10^{-19}\right)$ (See Table 2). The accuracy difference between illusory and fragmented conditions did not depend on difficulty level, although there was a trend toward a greater difference on the smaller rotation condition (two-way interaction: $F(2,48)=3.3, p=.08$ ). The marginal interaction probably arose from ceiling effects for the fragmented condition since there was no corresponding interaction in the reaction time data $(\mathrm{F}(2,48)=.82, \mathrm{p}=.37)$. Reaction time data were in other ways entirely predictable from the accuracy results, with faster performance in the fragmented than the illusory condition $(F(1,48)=11.4, p<.01)$, and faster performance in the easy than the hard condition $\left(\mathrm{F}(1,48)=65.7, \mathrm{p}<10^{-9}\right)$. The no-response trials were infrequent, occurring on only $3.9 \%$ of the trials on average. The frequency of no-response trials did not vary with difficulty level or task condition nor was there an interaction between difficulty and task condition (all p>.10). Note that one SZ patient exhibited chance task performance but was retained so as to have a more typical and representative patient sample. Most importantly, across all three ANOVAs (accuracy, RT, no-response frequency), there were no main effects or interactions with subject group (all p>.28; all partial eta squared<.055). We argue in the Discussion that these null results_-in combination with past studies (Keane et al., 2019)—suggest that certain brain network mechanisms in our SZ sample were playing a compensatory role. 
medRxiv preprint doi: https://doi.org/10.1101/2022.01.26.22269913; this version posted January 28, 2022. The copyright holder for this preprint (which was not certified by peer review) is the author/funder, who has granted medRxiv a license to display the preprint in perpetuity. It is made available under a CC-BY-NC-ND 4.0 International license .

\section{ABNORMAL BRAIN NETWORKS OF PERCEPTUAL ORGANIZATION}

Consistent with past results (Keane et al., 2021a; 2019), the fragmented and illusory conditions were highly correlated behaviorally across subjects (accuracy- $r=.67, p<10^{-7}$; RT$\left.\mathrm{r}=.85, \mathrm{p}<.10^{-11}\right)$, confirming that the two were reliant upon a common core of mechanisms. The correlations were robust and remained significant when calculated with non-parametric tests or after log-transforming the RT data.

Table 2. Task Performance

\begin{tabular}{|l|l|l|l|}
\multicolumn{1}{l}{} & HC & \multicolumn{1}{l}{ BP } & \multicolumn{1}{l}{ SZ } \\
\hline \% Correct, Illus & $82.9(3.0)$ & $80.0(3.5)$ & $79.6(3.4)$ \\
\hline \% Correct, Frag & $89.6(2.2)$ & $89.7(2.5)$ & $87.4(2.4)$ \\
\hline Reaction Time (s), Illus & $1.04(.07)$ & $.93(.08)$ & $1.06(.07)$ \\
\hline Reaction Time (s), Frag & $.94(.07)$ & $.84(.08)$ & $.99(.08)$ \\
\hline \% Slow Response, Illus & $4.3(2.6)$ & $0.4(3.0)$ & $5.2(2.9)$ \\
\hline \% Slow Response, Frag & $6.8(2.8)$ & $0.6(3.2)$ & $6.3(3.1)$ \\
\hline
\end{tabular}

Note. Mean values for each variable (with standard error of the mean)

\subsection{Group-averaged shape completion modulations were less pronounced in both patient groups because of increased inter-subject variability}

To consider whether specific parcels were differentially active within a group, we contrasted the illusory and fragmented conditions for each parcel. As reported previously, in the healthy sample, 36 parcels reached significance (Fig. 2); these belonged to the secondary visual (31\% of significant parcels), dorsal attention (25\%), frontoparietal (22\%), default mode (19\%), and cingulo-opercular networks (3\%) (Keane et al., 2021a). In bipolar patients, 6 parcels reached significance, with three falling within the dorsal attention network (bilateral PFt, $R \_T E 2 p$ ), two in the secondary visual network (R_FST, R_PH), and one in the frontoparietal network (R_IFSp). Finally, in schizophrenia patients, no parcel reached significance.

A potential objection is that patient groups demonstrated fewer modulated regions only because their sample sizes were smaller (15-16 subjects rather than 20 ). To address this concern, we re-ran the univariate analysis consecutively for all possible combinations of controls taken 15 at a time. About $96.4 \%$ of the 15,504 combinations produced more significant regions than the bipolar group (6) and 100\% produced more than the schizophrenia group (equivalent to $p<.04$ and $p<10^{-4}$, respectively, on a one-tailed test; see Fig. 2D). Thus, when parcel-wise modulations were averaged across subjects, fewer regions were significant in each patient group. 
medRxiv preprint doi: https://doi.org/10.1101/2022.01.26.22269913; this version posted January 28, 2022. The copyright holder for this preprint (which was not certified by peer review) is the author/funder, who has granted medRxiv a license to display the preprint in perpetuity. It is made available under a CC-BY-NC-ND 4.0 International license.

\section{ABNORMAL BRAIN NETWORKS OF PERCEPTUAL ORGANIZATION}

But what was causing patients to have fewer group-averaged modulations? One possibility is that the modulations occurred only weakly in each patient; another is that the modulations occurred strongly but in heterogeneous ways such that the effects would cancel out in a group analysis. To decide between these alternatives, we ran a single-subject univariate analysis contrasting the averaged illusory and fragmented response for each subject and parcel (see section 2.3.4 of the Methods). It was found that the average number of significantly modulated parcels did not differ between groups $(F(2,48)=.60, p=.55$, eta squared=.025; all $\mathrm{g}<.29$ on multiple comparisons; $M_{H C}=118, M_{B P}=100, M_{S Z}=98$ regions). Thus, completed shapes were distinctively represented in each group, but the engaged regions were more variable across patients than across the controls.

To better confirm that patients' modulations were more heterogeneous, we additionally correlated each subject's parcel-wise modulations to the respective group average (without that subject) and compared the resulting Fisher-Z-transformed correlations between groups. Controls differed from BPs and SZs $\left(t(33)=3.4, p=.002, g=1.14 ; t(34)=5.03, p<10^{-4}, g=1.65\right)$ but the two patient groups did not differ $(\mathrm{t}(29)=1.47, \mathrm{p}=.15, \mathrm{~g}=.51)$. 

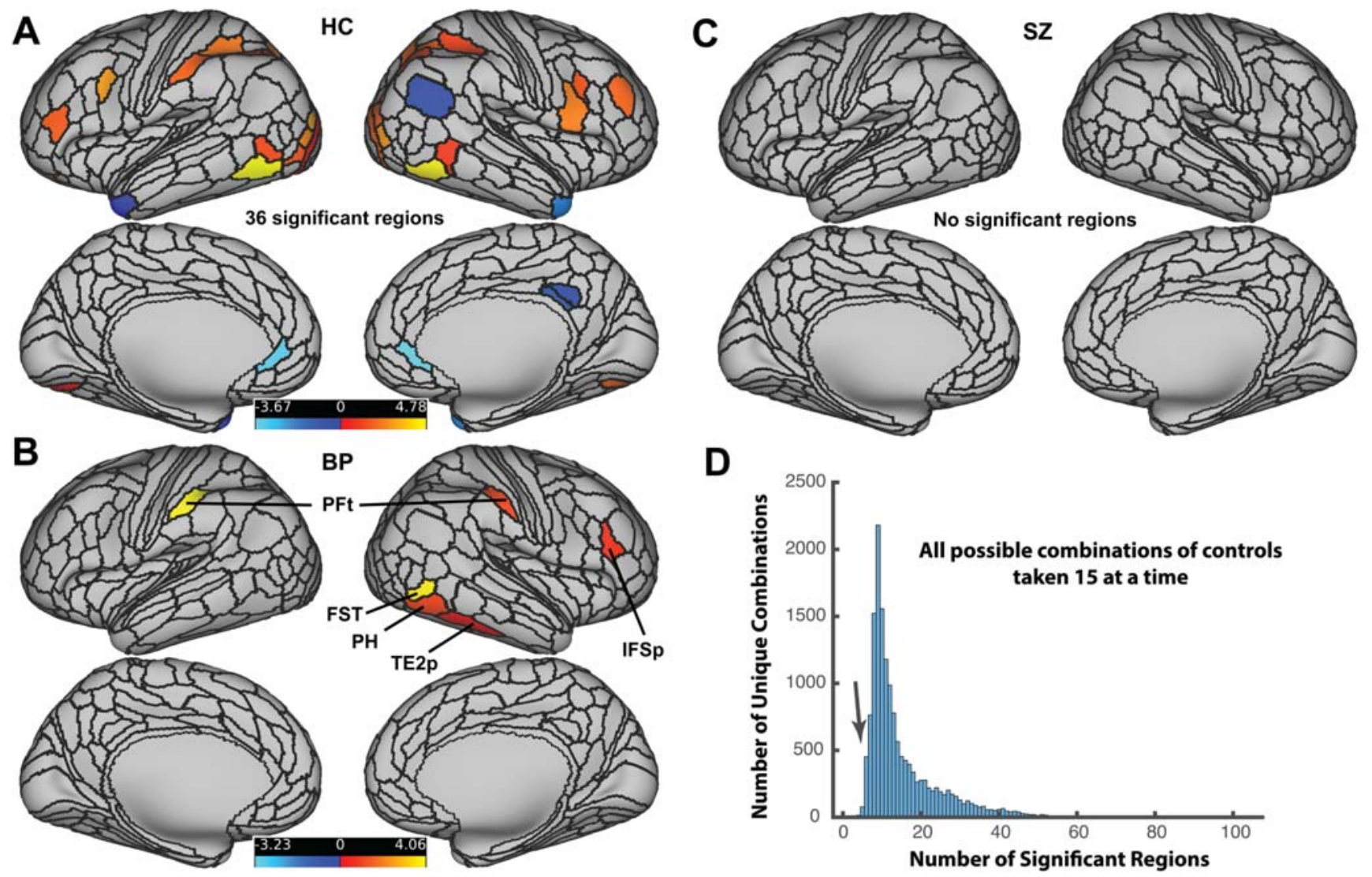

D

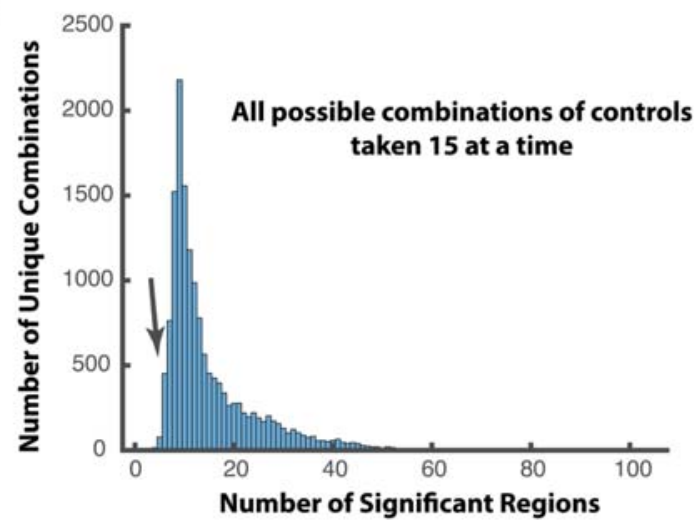

Fig. 2. (A-C) FDR-corrected activation difference amplitudes (Z-normalized) for all parcels for the illusory - fragmented contrast for healthy controls (HC), bipolar disorder patients (BP), and schizophrenia patients (SZ). Hot colors indicate regions that were more active for the illusory minus fragmented contrast; cool colors indicate the reverse. (D) To control for sample size, we re-ran the univariate analysis for all combinations of controls taken 15 at time (the number of subjects in the BP group). The arrow on the resulting histogram shows the number of combinations that resulted in exactly 6 significant regions (the number of significant regions for the BP group). Over $96 \%$ of the combinations for HCs had more than 6 significant regions. For more detailed information on the univariate task activation results for each group, see Extended Data Table 2-1, 2-2, and 2-3.

\subsection{Traces of shape completion were scattered over more networks in patients}

To determine the networks relevant to shape completion in each group, we ran a leave-tworuns-out MVPA, which assessed-for each subject and network — whether the illusory and fragmented betas from the training runs could be used to correctly classify the illusory and 
medRxiv preprint doi: https://doi.org/10.1101/2022.01.26.22269913; this version posted January 28, 2022. The copyright holder for this preprint (which was not certified by peer review) is the author/funder, who has granted medRxiv a license to display the preprint in perpetuity. It is made available under a CC-BY-NC-ND 4.0 International license .

\section{ABNORMAL BRAIN NETWORKS OF PERCEPTUAL ORGANIZATION}

fragmented betas from the two remaining runs. To determine the involvement of each network within a group, classification accuracy results were aggregated across subjects and compared to a null distribution (see Methods). Note that each subject's classification accuracy was calculated before group-averaging and so was insensitive to inter-subject variability in neural patterns. For healthy controls, the secondary visual network encoded the modulations, as already reported (accuracy $=63 \%, p_{\text {corr }}=.001$ ) (Keane et al., 2021a). The shape completion network also encoded the modulations (accuracy $=60 \%, p_{\text {corr }}=.008$ ), which of course was expected since its regions were defined on those same subjects (ibid). For schizophrenia patients, four networks encoded the modulations: secondary visual (accuracy $=63 \%$, $p_{\text {corr }}<.003$ ), dorsal attention (accuracy $=61 \%, p_{\text {corr }}=.009$ ), default mode (accuracy $=59 \%$, $p_{\text {corr }}<.05$ ), and shape completion (accuracy $=57 \%, p_{\text {corr }}<.05$ ). Finally, for bipolar patients, seven significant networks encoded the modulations: secondary visual (accuracy $=69 \%, p_{\text {corr }}<.0001$; somatomotor (accuracy $=59 \%, p_{\text {corr }}=.02$ ), cingulo-opercular (accuracy $=60 \%, p_{\text {corr }}=.009$ ), dorsal attention (accuracy $=71 \%, p_{\text {corr }}<.0001$ ), language (accuracy $=59 \%, p_{\text {corr }}=.03$ ), frontoparietal (accuracy $=59 \%, p_{\text {corr }}=.009$ ), and shape completion (accuracy=68\%; $p_{\text {corr }}=.0004$ ). Thus, after discounting between-subject variability, multivariate traces of shape completion were distributed through more networks in each patient group relative to controls. Moreover, even though the shape completion network was defined on controls, decoding accuracies for these regions were numerically similar to or even higher in patients than controls, showing that this network was relevant to shape completion irrespective of diagnostic status. 


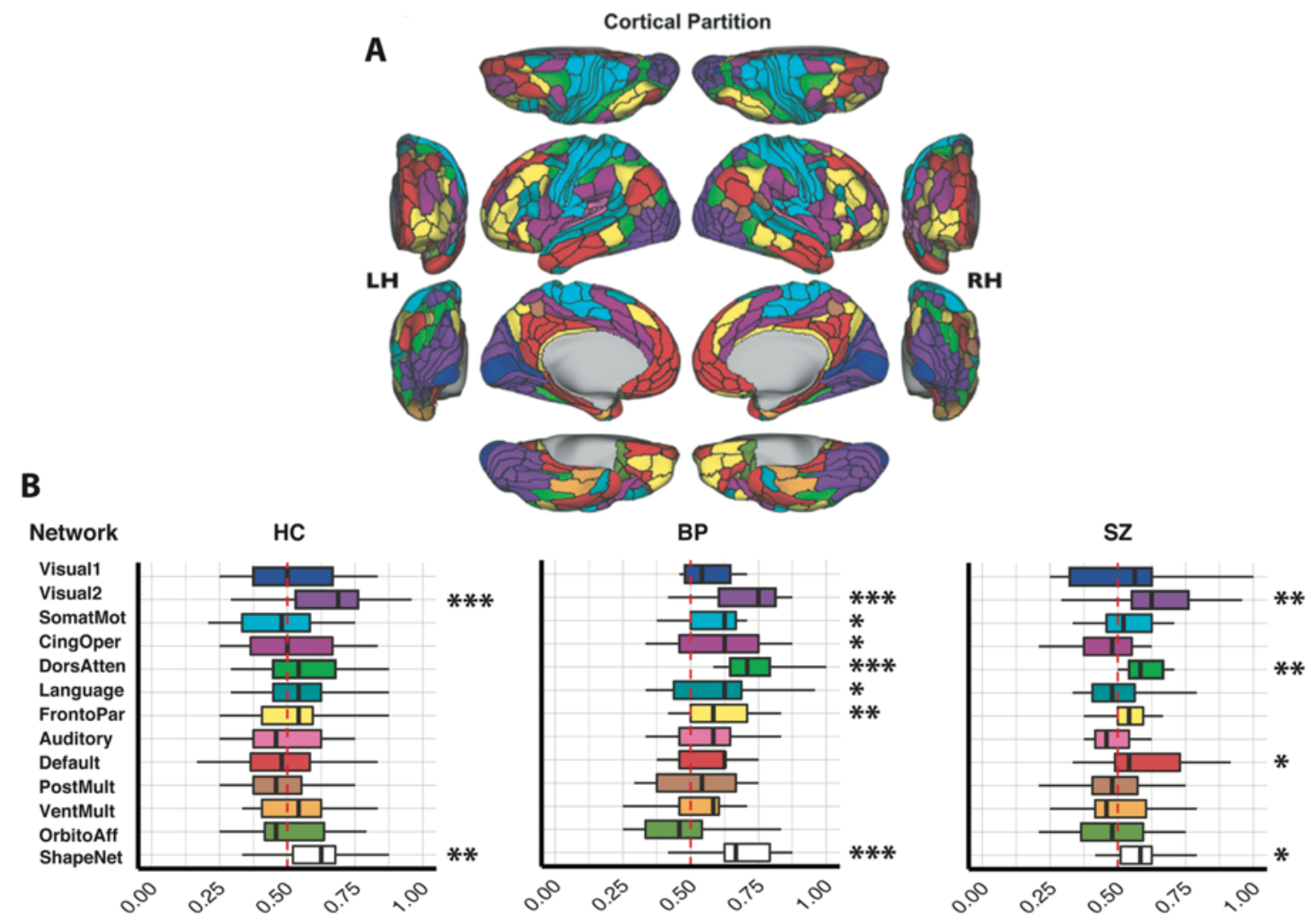

C

Classifier Accuracy: Illusory vs. Fragmented (Proportion Correct)

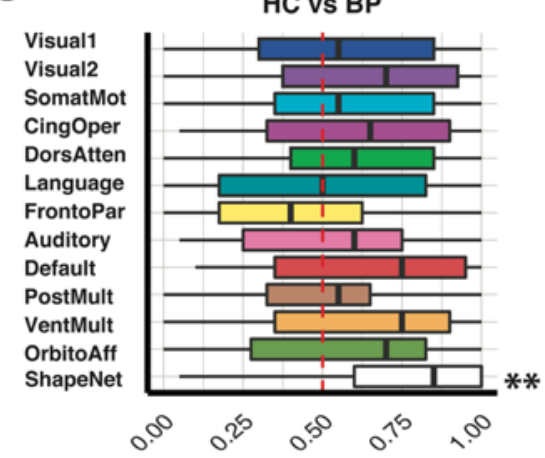

HC vs SZ

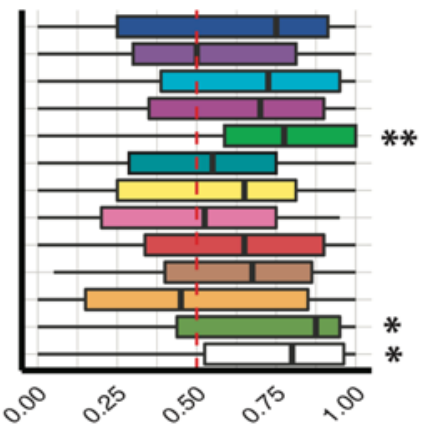

BP vs SZ

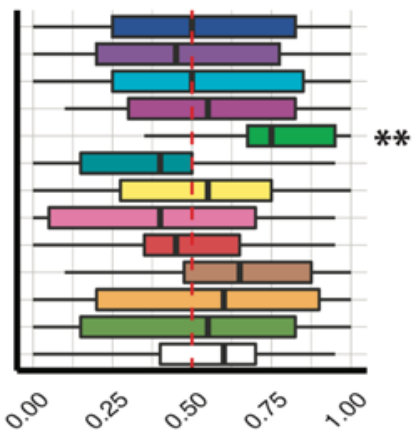

Classifier Accuracy: Group1 vs Group2 (Proportion Correct)

Fig. 3. (A) The twelve functional networks (Ji et al., 2019) are color-coded to match panels $B$ and C. Parcels composing the shape completion network ("ShapeNet") are shown in Fig 2A (see also Fig. 2 of Keane et al. (2021a). (B) Box plots depicting illusory/fragmented classification accuracy for each group using leave-two-runs-out cross-validation. The red dotted lines demarcate $50 \%$ performance. (C) Box plots depicting group classification accuracy for each pair of groups using repeated split-half cross-validation, where the features correspond to illusory/fragmented differences. See text for additional classification statistics. ${ }^{*} p_{\text {corr }}<.05,{ }^{* *} p_{\text {corr }}<.01,{ }^{* * *} p_{\text {corr }}<=.001$. 
medRxiv preprint doi: https://doi.org/10.1101/2022.01.26.22269913; this version posted January 28, 2022. The copyright holder for this preprint (which was not certified by peer review) is the author/funder, who has granted medRxiv a license to display the preprint in perpetuity. It is made available under a CC-BY-NC-ND 4.0 International license .

ABNORMAL BRAIN NETWORKS OF PERCEPTUAL ORGANIZATION

\subsection{Dorsal attention and orbito-affective networks distinguished schizophrenia patients} To consider whether groups could be distinguished in cross-parcel patterns, we trained MVPA classifiers separately for the 12 functional networks (Ji et al., 2019) plus the shape completion network mentioned above (Keane et al., 2021). For each pair of subject groups and for each network, the classifier used illusory/fragmented activation differences to categorize subjects by their group membership (see Methods). After FDR correction, only the shape completion network could distinguish bipolar patients and healthy controls $\left(p_{\text {corr }}=.004\right.$, sensitivity ${ }_{B P}=.49$, specificity $_{\mathrm{BP}}=.89, \mathrm{AUC}=.81$ ). The networks that could distinguish schizophrenia patients from healthy controls were the dorsal attention $\left(p_{\text {corr }}=.002\right.$, sensitivity $\mathrm{sz}=.74$, specificity $\mathrm{sz}_{\mathrm{sz}}=.74$, $\mathrm{AUC}=.86)$, orbito-affective $\left(\mathrm{p}_{\mathrm{corr}}=.02\right.$, sensitivity $\mathrm{sz}=.65$, specificitysz $\left.=.72, \mathrm{AUC}=.77\right)$, and the shape completion networks ( $p_{\text {corr }}=.01$, sensitivity $s z=.51$, specificity sz $_{s z} .82, A \cup C=.76$ ). When comparing bipolar and schizophrenia patients, only the dorsal attention network reached significance ( $p_{\text {corr }}=.008$, sensitivitysz $=.73$, specificity sz $_{s}=.73, A \cup C=.87$ ). To summarize, patterns of dorsal attention task activations could distinguish schizophrenia patients from the other groups; patterns in the shape completion network coalition could do the same with healthy controls (though these results will need to be replicated given circularity), and the orbitoaffective network was also able to distinguish SZs from controls.

\subsection{Shape completion parcels were densely and similarly inter-connected in each group}

To determine how task-modulated regions were functionally interconnected and how these connections might differ between groups, we first derived a whole-cortex RSFC with multiple regression (see Methods). We then compared each subject's average within-network versus out-of-network connection weight across the 36 shape completion network parcels. Shape completion regions cohered more strongly with one another than with other regions for each group (HC: $t(18)=21.4, p<10^{-13}$; BP: $t(12)=19.5, p<10^{-9}$; SZ: $\left.t(14)=14.6, p<10^{-9}\right)$. Interestingly, group differences in these within-versus-between difference values were non-significant and small in magnitude $(F(2,44)=.4, p=.7$; eta-squared $=.016$; Hedges $\mathrm{g}<=.25$ on multiple comparisons). Thus, each group had a similarly robust shape completion network, as measured by resting-state connections. 
medRxiv preprint doi: https://doi.org/10.1101/2022.01.26.22269913; this version posted January 28, 2022. The copyright holder for this preprint (which was not certified by peer review) is the author/funder, who has granted medRxiv a license to display the preprint in perpetuity. It is made available under a CC-BY-NC-ND 4.0 International license .

\section{ABNORMAL BRAIN NETWORKS OF PERCEPTUAL ORGANIZATION}

To examine whether specific connections were obviously aberrant in any one group, we compared via t-tests the individual connection weights on the shape completion network coalition and, for completeness, the full RSFC matrix. After FDR correction, there were no significant differences on any pairwise comparisons. Using the same MVPA procedure described above, we also considered whether patterns of functional connection weights could differ between groups; this was done for the shape completion network coalition and all 12 resting-state networks. There were no significant differences between any pair of groups for

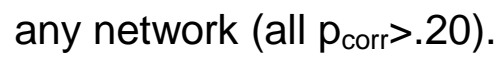

We then aimed to directly quantify the apparent similarity of RSFC profiles across groups with Mantel permutation tests, which account for the non-independence of FC matrix values (Diniz-Filho et al., 2013). We found similar RSFC for each pair of groups for the $360 \mathrm{x}$ 360 matrix (HC vs. BP: $r=.76, p<10^{-7}$; HC vs. SZ: $r=.77, p<10^{-7}$; BP vs. $\mathrm{HC}: r .=.73, p<10^{-7}$ ) and for the $36 \times 36$ shape completion network (HC vs. BP: $r=.93, p<10^{-7} ; \mathrm{HC}$ vs. SZ: $r=.93, p<10^{-7}$; BP vs. HC: $\left.r=.91, p<10^{-7}\right)$. These results show that the shape completion network was approximately intact in each patient group and that eliciting more obvious group differences in neural activity requires either larger samples (Spronk et al., 2020; J. Zhang et al., 2021) or task engagement (Greene et al., 2018; Sripada et al., 2020). 
medRxiv preprint doi: https://doi.org/10.1101/2022.01.26.22269913; this version posted January 28, 2022. The copyright holder for this preprint (which was not certified by peer review) is the author/funder, who has granted medRxiv a license to display the preprint in perpetuity.

It is made available under a CC-BY-NC-ND 4.0 International license .

\section{ABNORMAL BRAIN NETWORKS OF PERCEPTUAL ORGANIZATION}

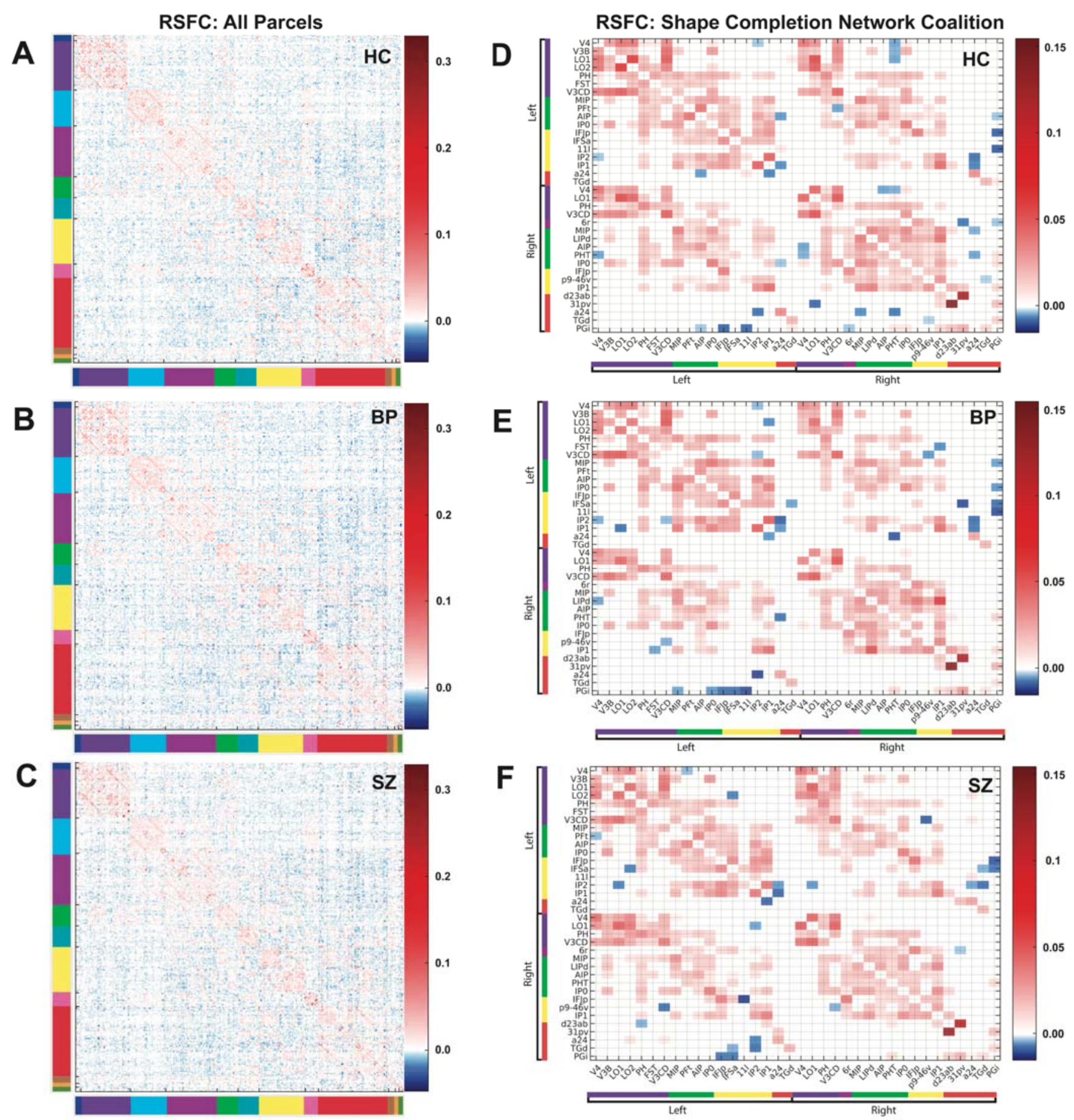

Fig. 4. Resting-state functional connectivity (RSFC) matrices were similar for each subject group. (A-C) A full unthresholded 360x360 RSFC matrix showing group-averaged regression coefficients for healthy controls, bipolar disorder patients, and schizophrenia patients. The blue/red colors indicate the degree to which a given parcel time series was predicted by all remaining parcels. Colors on the outskirts of the matrices indicate the network to which a given region belonged (see Fig. 3). (D-F) Thresholded (FDR-corrected) group-averaged resting-state connections are shown for the shape completion 
medRxiv preprint doi: https://doi.org/10.1101/2022.01.26.22269913; this version posted January 28, 2022. The copyright holder for this preprint (which was not certified by peer review) is the author/funder, who has granted medRxiv a license to display the preprint in perpetuity. It is made available under a CC-BY-NC-ND 4.0 International license .

\section{ABNORMAL BRAIN NETWORKS OF PERCEPTUAL ORGANIZATION}

network regions. These were ordered first by hemisphere and then by network. Each trio of matrices was scaled in the same way across groups to enable cross-group comparisons.

\subsection{Resting-state connections likely subserve shape completion in each subject group} A recently-developed predictive modeling approach-activity flow mapping ("ActFlow”) (Cole et al., 2016)_has demonstrated that resting-state connections are likely relevant to shape completion in healthy controls (Keane et al., 2021a). This method computes the activation difference (illusory minus fragmented) in a held-out "target" parcel as the linear weighted sum of the activation differences in all other parcels, with the weights being given by the restingstate connections to the target (Fig. 5). This algorithm is based on neural network simulations, and can thus be thought of as a rough simulation of the movement of task-evoked activity that likely contributed to each brain region's task-evoked activity level, which in turn can provide evidence that the resting-state connections mechanistically supported shape completion. Prediction accuracies (correlations between the actual and predicted activation differences computed for each individual subject) were well above zero at the whole-cortex level for healthy controls, bipolar patients, and schizophrenia patients ( $\mathrm{HC}: r=.64, p<10^{-9}$; $\mathrm{BP}: r=.63$, $\left.\mathrm{p}<10^{-8} ; \mathrm{SZ}: \mathrm{r}=.57, \mathrm{p}<10^{-6}\right)$. Restricting the modeling to the shape completion network regions yielded similarly strong results for each group (HC: $r=.66, p<10^{-7} \mathrm{BP}: r=.56, p<10^{-4}$; SZ: $r=.57$, $\mathrm{p}<10^{-9}$ ) suggesting that much of shape completion can be gleaned by only looking at these 36 parcels. Between-group comparisons of these correlations (with Fisher-Z transforms) yielded no significant differences when using all 360 cortical parcels $(F(2,44)=.9, p=.42$; eta squared=.04; on pairwise comparisons, all $\mathrm{g}<.41$ and all $\mathrm{p}>.23$ uncorrected) or when using only the 36 shape completion regions $(F(2,44)=1.4, p=.25$; eta squared=.06; on pairwise comparisons, all $\mathrm{g}<.5$ and all $\mathrm{p}>.14$ uncorrected). Taken together, these results demonstrate that the resting-state connectivity data could be used to model shape completion activations in each group. These results attest to the appropriateness of the brain activity flow mapping procedure for understanding shape completion in healthy and schizo-bipolar populations and lend credibility to the modeling results below.

As already noted, group-overlap ActFlow estimates exceed subject-level estimates partly because subjects neurally represent the stimuli in similar ways and averaging over subjects removes noise (Cole et al., 2016). This means that measuring the difference between 
medRxiv preprint doi: https://doi.org/10.1101/2022.01.26.22269913; this version posted January 28, 2022. The copyright holder for this preprint (which was not certified by peer review) is the author/funder, who has granted medRxiv a license to display the preprint in perpetuity. It is made available under a CC-BY-NC-ND 4.0 International license.

\section{ABNORMAL BRAIN NETWORKS OF PERCEPTUAL ORGANIZATION}

subject- and group-overlap estimates (after Fisher Z transform) can provide a way to quantify inter-subject agreement in neural representations. In group-to-group comparisons, the ActFlow accuracy difference (group - subject-overlap) was larger for controls than for bipolar patients $\left(\mathrm{t}(30)=4.8, \mathrm{p}<10^{-4}, \mathrm{~g}=1.7\right)$ and $\mathrm{SZ}$ patients $\left(\mathrm{t}(32)=5.9, \mathrm{p}<10^{-5}, \mathrm{~g}=2.0\right)$, but similar between the two patient groups $(\mathrm{t}(26)=-1.4, \mathrm{p}=.17, \mathrm{~g}=.52)$. While other factors may contribute to an increased group-level ActFlow estimate, these results provide additional converging evidence of increased heterogeneity among patients. 
medRxiv preprint doi: https://doi.org/10.1101/2022.01.26.22269913; this version posted January 28, 2022. The copyright holder for this preprint (which was not certified by peer review) is the author/funder, who has granted medRxiv a license to display the preprint in perpetuity.

It is made available under a CC-BY-NC-ND 4.0 International license .

\section{ABNORMAL BRAIN NETWORKS OF PERCEPTUAL ORGANIZATION}

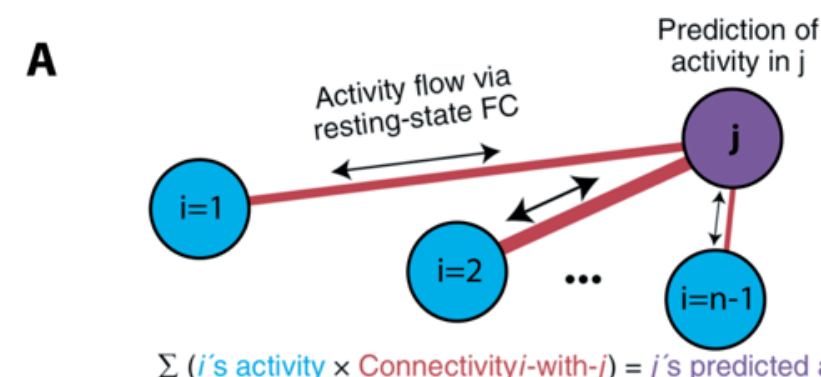

$\Sigma$ (i's activity $\times$ Connectivity $i$-with $-j)=j$ 's predicted activity

B

Actual task activation

$i \neq j$ differences

\section{Predicted from resting-state \\ functional connectivity}

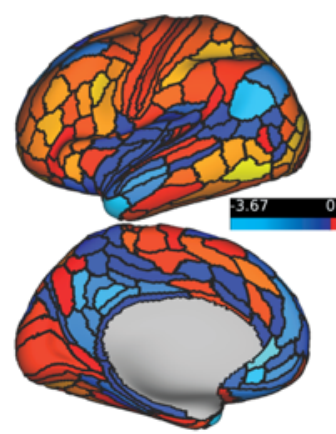

C
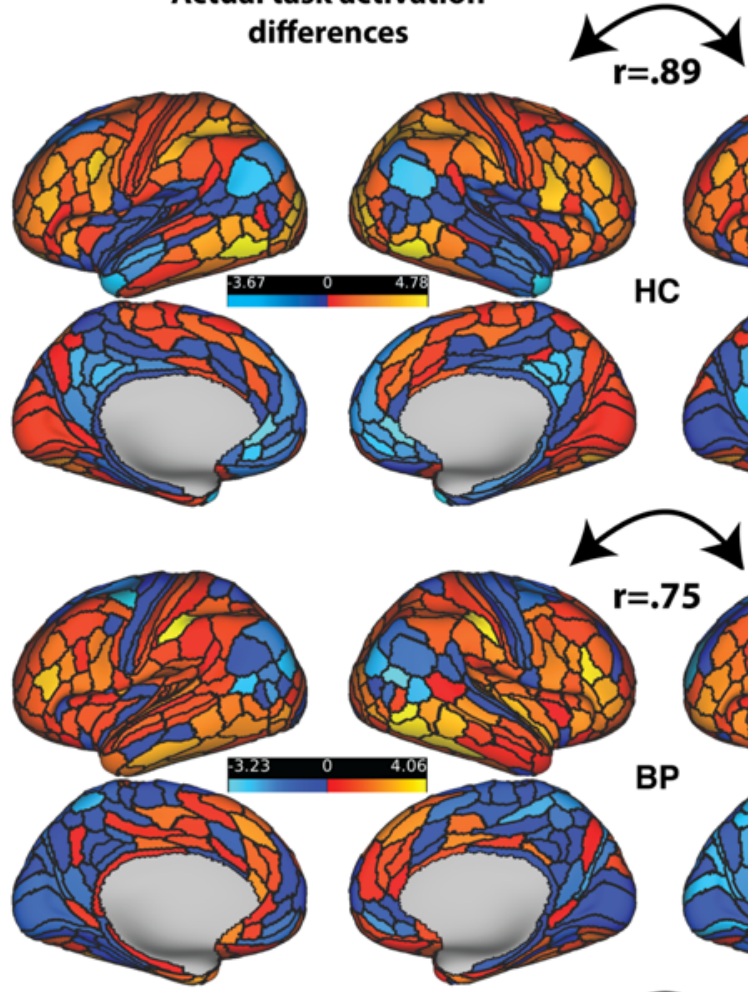

D

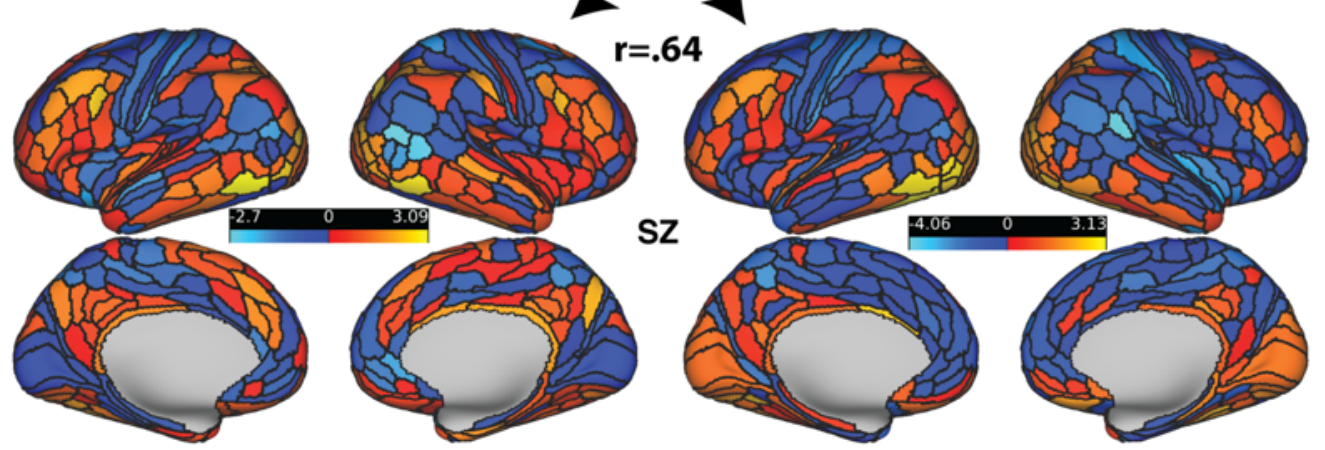

Fig. 5. Activity flow mapping results for visual shape completion in each group. (A) For each subject, the task activation differences (illusory-fragmented) in a held-out parcel (j) is given by the dot product between the activation differences in the remaining parcels (regions i) and the resting-state connection strengths (betas) between i and j. (B-D) Unthresholded z-normalized activation differences (illusory fragmented) as compared to those that were predicted via ActFlow using resting-state connections for 
medRxiv preprint doi: https://doi.org/10.1101/2022.01.26.22269913; this version posted January 28, 2022. The copyright holder for this preprint (which was not certified by peer review) is the author/funder, who has granted medRxiv a license to display the preprint in perpetuity. It is made available under a CC-BY-NC-ND 4.0 International license .

\section{ABNORMAL BRAIN NETWORKS OF PERCEPTUAL ORGANIZATION}

each subject group. The depicted correlations (ActFlow accuracy) show group-level overlap between predicted and actual activation differences (after averaging modulations across subjects). The descending correlation values across groups ( $\mathrm{HC}>\mathrm{BP}>\mathrm{SZ}$ ) likely reflect the increasing inter-subject heterogeneity in neural representations of completed shape.

\subsection{Potentially reduced feedback activity from dorsal attention to secondary visual networks in schizophrenia}

We have shown that-in healthy controls - the dorsal attention network can model activity in the secondary network via ActFlow, potentially reflecting feedback to mid-level visual areas (Keane et al., 2021a). Does the same conclusion hold true for patients? To consider this question, we computed a single correlation between the actual and estimated parcel difference values (illusory-fragmented) across the 54 secondary visual network parcels in the shape completion network coalition. We then recomputed this correlation, when each of the 54 parcels could also be predicted by parcels and connections from the 23 dorsal attention regions (see Fig. 6). Finally, we Fisher-z transformed the correlations, subtracted the two, and then performed a one-sample t-test to see if the correlations increased as a result of the network's inclusion. As shown in Fig. 6E, the dorsal attention network improved the predictions for the secondary visual network in healthy controls $\left(\Delta r \approx \Delta r_{Z}=.11 ; t(18)=3.3, p=.004\right.$, $g=.76)$ and bipolar patients $\left(\Delta r \approx \Delta r_{z}=.09 ; t(12)=3.7, p=.003, g=1.03\right)$, but not in schizophrenia patients $\left(\Delta r \approx \Delta r_{Z}=.03 ; t(14)=1.2, p=.25, g=.31\right)$. Note that the contribution of the dorsal attention network was determined for each subject and thus was not sensitive to group-averaging. When restricting the analysis to the 11 secondary visual and 9 dorsal attention regions that composed the shape completion network, qualitatively the same results arose as before for HCs $\left(\Delta r \approx \Delta r_{Z}=.34, t(18)=2.8, p=.01, g=.64\right)$, BPs $\left(\Delta r \approx \Delta r_{Z}=.26, t(12)=2.2, p=.049, g=.61\right)$, and $\mathrm{SZs}\left(\mathrm{r} \approx \Delta \mathrm{r}_{\mathrm{Z}}=.06 ; t(14)=.8, p=.42, g=.21\right)$. No other network could model the secondary visual network in any group for either the full set of 360 parcels or the shape completion network (all $p>.05$ ). A caveat is that these $\Delta$ Fisher- $Z$ values did not differ between groups, although pairwise comparisons between $\mathrm{SZ}$ and HCs approached significance when using either all cortical regions or just the shape completion regions $(\mathrm{p}=.09, \mathrm{~g}=.59 ; \mathrm{p}=.07, \mathrm{~g}=.63)$. It can nevertheless be concluded that the dorsal attention network fails to robustly model the secondary visual network in schizophrenia, perhaps because of reduced feedback from dorsal attention to secondary visual areas. 
medRxiv preprint doi: https://doi.org/10.1101/2022.01.26.22269913; this version posted January 28, 2022. The copyright holder for this preprint (which was not certified by peer review) is the author/funder, who has granted medRxiv a license to display the preprint in perpetuity.

It is made available under a CC-BY-NC-ND 4.0 International license .

\section{ABNORMAL BRAIN NETWORKS OF PERCEPTUAL ORGANIZATION}

A

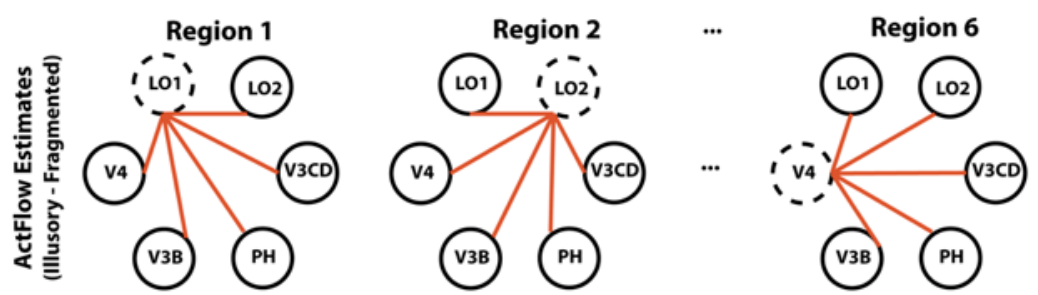

B

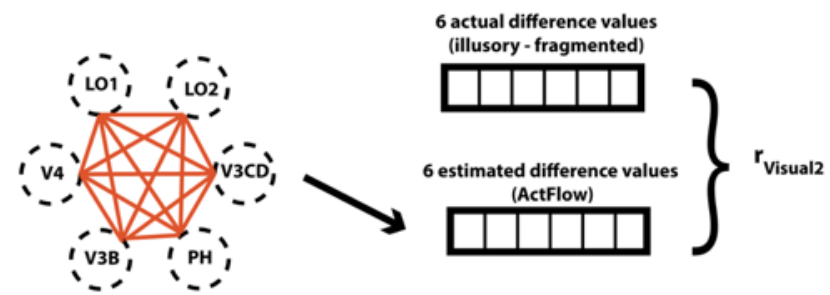

C

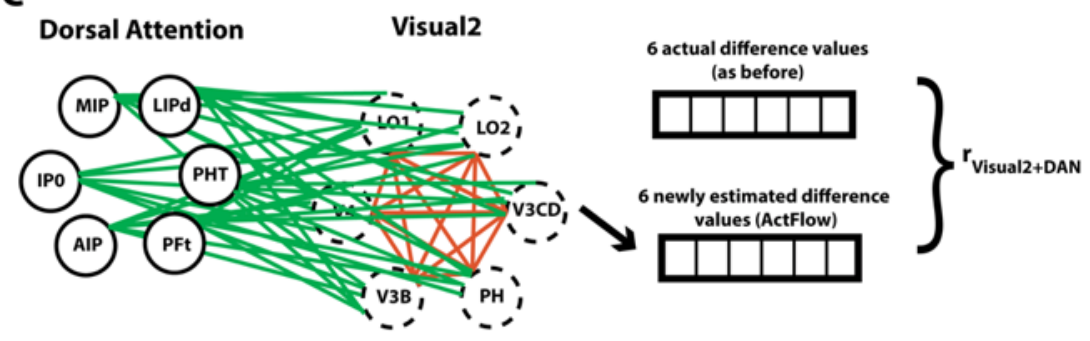

D
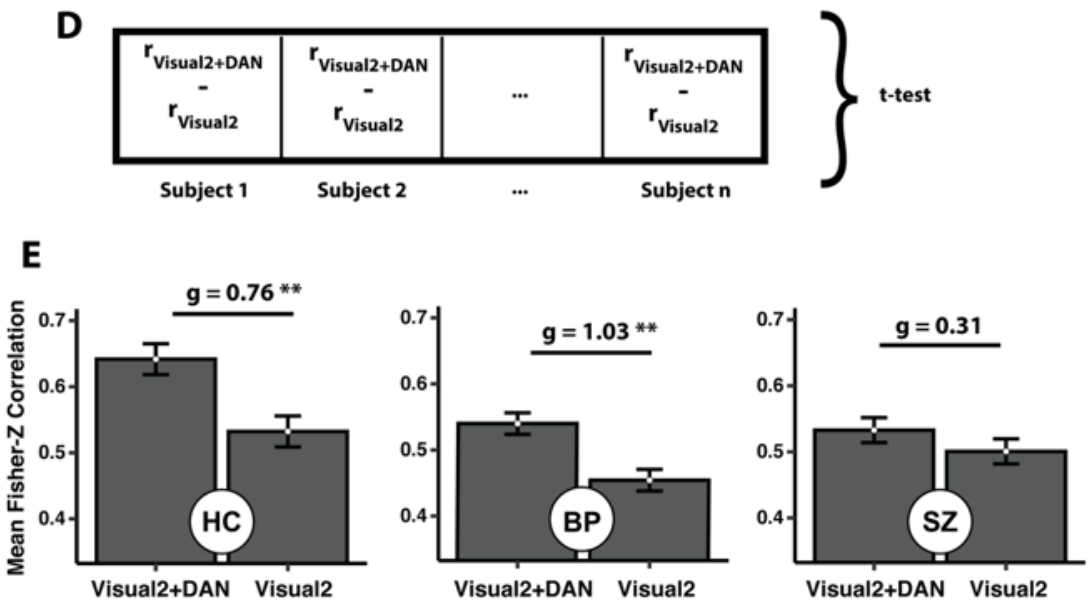

Fig. 6. Gauging modeling contributions of the dorsal attention network to the secondary visual network (Visual2). (A) For a given subject, task activation differences for each significant Visual2 parcel were estimated (dotted circles) using actual task activation differences in the remaining parcels (solid circles) and their resting-state connections (red lines). For illustration, only six regions are shown for each network. (B) ActFlow accuracy was defined as the correlation between actual and estimated task activation differences, across the Visual2 parcels. (C) Task activation differences were again estimated via ActFlow, except that, this time, the connections and activation differences from dorsal attention 
medRxiv preprint doi: https://doi.org/10.1101/2022.01.26.22269913; this version posted January 28, 2022. The copyright holder for this preprint (which was not certified by peer review) is the author/funder, who has granted medRxiv a license to display the preprint in perpetuity. It is made available under a CC-BY-NC-ND 4.0 International license .

\section{ABNORMAL BRAIN NETWORKS OF PERCEPTUAL ORGANIZATION}

regions could also contribute. (D) The difference between the original and re-calculated estimates was computed for each subject (after a Fisher Z-transform) and directly compared across subjects within a group via a one-sample (or paired) t-test. (E) The dorsal attention network could significantly improve ActFlow estimates in the secondary visual network in controls and bipolar patients, but not in schizophrenia patients. Errors $=+/-S E M^{* *} p<.01$. Figure is adapted from Keane et al. (2021a).

\subsection{Dorsal attention network activity was related to cognitive disorganization} Increased cognitive disorganization has been associated with poorer shape completion and abnormal oscillations, as noted (Keane et al., 2019; Spencer et al., 2004; Spencer and Ghorashi, 2014). Dorsal attention network modulations can also distinguish SZ patients from other subject groups (Fig. 3C). Can these variables be linked more directly? To consider the question, we individually regressed each clinical variable onto the modulations of the 23 dorsal attention parcels using leave-one-out cross-validation with permutation testing (see Methods). Across all 31 patients, the modulations were indeed related to cognitive disorganization $(r=.65$, $\mathrm{MAE}=.78, \mathrm{p}=.007)$. These results were robust and would also be significant if we were to use leave-two-out or 10 -fold cross-validation (both $p<=.01$ ).

\section{Discussion}

Visual shape completion plays a critical role in extracting object shape, size, position, and number from edge elements dispersed across the field of view. Prior electrophysiological and psychophysical work has suggested that schizophrenia patients properly form illusory contours at initial stages of processing but potentially exhibit later-stage differences in posterior parietal or frontal-temporal regions. However, these findings have not been corroborated with other neuroscience methods and were generally limited by their lower spatial resolution. Here, we leveraged recent tools in computational neuroimaging to investigate the functional connections and brain networks that may differ in schizophrenia during shape completion. We additionally considered whether such differences arise in bipolar disorder or whether they vary monotonically with illness factors that cut across the schizo-bipolar spectrum.

Four major findings emerged. First, according to both the univariate task analyses and the brain activity flow mapping modeling, there was increased inter-patient heterogeneity in the neural representation of completed shape. Second, when discounting heterogeneity, patients 
medRxiv preprint doi: https://doi.org/10.1101/2022.01.26.22269913; this version posted January 28, 2022. The copyright holder for this preprint (which was not certified by peer review) is the author/funder, who has granted medRxiv a license to display the preprint in perpetuity. It is made available under a CC-BY-NC-ND 4.0 International license .

\section{ABNORMAL BRAIN NETWORKS OF PERCEPTUAL ORGANIZATION}

encoded completed shapes with a similar number of regions but a larger number of networks. Third, the dorsal attention network was differentially active in SZ compared to the other groups (AUCs>.85; sensitivities>.72; specificities>.72) and was modelled as not influencing the secondary visual network (in contrast to the other groups, who did show an influence). Fourth, dorsal attention modulations across all patients were related to cognitive disorganization severity. Below, we discuss these findings in more detail, identify potential limitations, and suggest future directions.

\subsection{A case for compensatory brain network mechanisms in schizophrenia}

We argue that at least some of the brain network differences in SZ were compensatory. First, shape completion deficits-quantified as the illusory/fragmented performance difference on the fat/thin task—have been established using an efficient Bayesian adaptive staircase (Kontsevich and Tyler, 1999) with larger samples (134 non-affective psychosis patients, 66 HCs; $d=.67, p<10^{-4}$ ) (Keane et al., 2019); this difference grew larger when only patients with intact "fragmented" performance were included ( $n=99$ patients; $\left.d=.80, p<10^{-6}\right)$. Second, the $\mathrm{SZ} / \mathrm{HC}$ shape completion difference in the current study was small but in the right direction and within range of a previous report using the (less efficient) method-of-constant-stimuli ( $g=.10$, $95 \% \mathrm{Cl}=[-.54 .74])$ versus $\mathrm{g}=.67$ in Keane et al., in press). Third, whereas earlier studies presented a $200 \mathrm{~ms}$ pac-man configuration followed by a mask, the current study presented 250 ms pac-men followed by a 2750 ms blank screen (to ensure a more robust BOLD response). Masking effectively caps stimulus processing time and may limit the opportunity for brain network mechanisms to compensate for an initially aberrant shape completion process. Future studies will need to consider brain network differences as a function of effective presentation time.

\subsection{Aberrant dorsal attention network activity in schizophrenia}

Across multiple analyses, the dorsal attention network was aberrant in SZ. While it is not possible to tease apart feedforward and feedback activity using the hemodynamic response, we suggest that dorsal attention network dysfunction may disrupt top-down attentional amplification (Berkovitch et al., 2017; 2018). Such amplification may be needed to properly notice and use illusory contours for shape discrimination (Keane et al., 2012). This disruption 
medRxiv preprint doi: https://doi.org/10.1101/2022.01.26.22269913; this version posted January 28, 2022. The copyright holder for this preprint (which was not certified by peer review) is the author/funder, who has granted medRxiv a license to display the preprint in perpetuity. It is made available under a CC-BY-NC-ND 4.0 International license .

\section{ABNORMAL BRAIN NETWORKS OF PERCEPTUAL ORGANIZATION}

has been linked specifically to cognitive disorganization, NMDA receptor hypofunction, and gamma band synchrony abnormalities, all of which characterize the schizophrenia phenotype (Berkovitch et al., 2017). As already intimated above, muted amplification may be less behaviorally consequential under prolonged (unmasked) viewing conditions, when other compensatory mechanisms may become available.

At the same time, the dorsal attention network encoded completed shapes in the SZ group but not in controls. We speculate that this network may compensate for poor top-down modulation by carrying out computations ordinarily performed by vision or by interfacing with other non-visual networks. Tests with larger samples are needed to directly test this assertion.

The foregoing results converge with those of earlier SZ studies, showing abnormal dorsal stream contributions to motion perception (O'Donnell et al., 1996), stereopsis (Schechter et al., 2006) and fragmented object recognition (Foxe et al., 2001). Visual working memory deficits (and broader indices of cognition) have also been attributed to abnormal activation in posterior parietal cortex (Hahn et al., 2018), which overlaps with the dorsal attention network. Taken together, the dorsal attention network may be a viable target for improving cognition, attention, and perception via neurostimulation, biofeedback, or pharmacological interventions.

\subsection{Orbitofrontal differences during visual perception in schizophrenia}

We speculated in past psychophysical investigations that orbitofrontal cortex (OFC) dysfunction may underlie shape completion abnormalities in schizophrenia (Keane et al., 2014). This was considered reasonable since: i) the OFC is differentially active $300 \mathrm{~ms}$ after stimulus onset during Kanizsa shape detection tasks in healthy adults (Halgren et al., 2003); ii) OFC contributes to object recognition under impoverished viewing conditions (Bar, 2003); and iii) gray matter volume in the region gradually shrinks over the course of the illness, especially among persons with thought disorder (Nakamura et al., 2008). In our sample, orbito-affective network patterns differentiated SZs and HCs though it could not distinguish any other groups. The orbito-affective network overlaps with posterior orbitofrontal cortex, which is associated with "reward processing" (Kahnt et al., 2010) and is strongly connected to the ventral striatum, the substantia nigra/ventral tegmental area, and the globus pallidus (Ji et al., 2019). Some of these same regions are routinely found to be hyperconnected to visual cortex in SZ (Anticevic 
medRxiv preprint doi: https://doi.org/10.1101/2022.01.26.22269913; this version posted January 28, 2022. The copyright holder for this preprint (which was not certified by peer review) is the author/funder, who has granted medRxiv a license to display the preprint in perpetuity. It is made available under a CC-BY-NC-ND 4.0 International license .

\section{ABNORMAL BRAIN NETWORKS OF PERCEPTUAL ORGANIZATION}

et al., 2014; Damaraju et al., 2014) and are associated with dopaminergic dysregulation in in unmedicated schizophrenia patients (Horga et al., 2016). While it is outside the scope of this work, it is worth investigating the cooperation between these subcortical structures and the orbitofrontal cortex as SZ patients attempt to recognize partly visible shapes.

\subsection{Bipolar disorder and schizophrenia: more heterogeneity and more diffuse neural representations}

Task modulations were more heterogeneous in each patient group relative to controls (both g>1.1) and these were corroborated by the ActFlow heterogeneity analyses (both $g>1.7$ ). Heterogeneity in cognitive task performance, symptoms, and clinical course has been wellknown for decades (Alda, 2004; Raffard and Bayard, 2012) but such pronounced differences in the arena of perception, to our knowledge, has not been reported for these two disorders. A major task in future studies will be to understand its underlying causes. The two disorders were also similar in that completed shapes were encoded across a broader range of networks. The reason for this distributed neural representation is unknown but could be because computations ordinarily performed by vision could have been outsourced to nominally nonvisual networks; or they could be byproducts of a less modularized brain network architecture (Ma et al., 2020).

\subsection{Addressing limitations}

The most obvious limitation was the sample size. Note however that three key results were shown via two group comparisons: more heterogeneity in each patient group, more relevant networks in each patient group, and more abnormal dorsal attention network activity in SZs relative to the other groups. Because these differences were essentially shown twice with clinically and demographically well-matched groups (Table 1) and because network-based effects are much more readily detected than region-based ones (Cremers et al., 2017; Noble et al., 2021), sample size concerns were mitigated. Likewise, the cognitive disorganization correlation was anticipated from past work (Keane et al., 2019; Spencer et al., 2004; Spencer and Ghorashi, 2014) and was shown with multiple forms of cross-validation using the combined patient sample $(n=31)$. 
medRxiv preprint doi: https://doi.org/10.1101/2022.01.26.22269913; this version posted January 28, 2022. The copyright holder for this preprint (which was not certified by peer review) is the author/funder, who has granted medRxiv a license to display the preprint in perpetuity. It is made available under a CC-BY-NC-ND 4.0 International license .

\section{ABNORMAL BRAIN NETWORKS OF PERCEPTUAL ORGANIZATION}

Another limitation is that patients were on medication. Note, however, that the patient groups did not significantly differ on olanzapine equivalents and prior behavioral and electrophysiological studies found no relationships between shape completion and the type/dose of neuroleptics (Foxe et al., 2005; Keane et al., 2019).

It is also unlikely that group differences in eye movements confounded our results since: 1) pac-men locations were equidistant from fixation, equally informative within a trial, and matched between conditions, reducing the chance of systematic task condition differences; 2) the illusory and fragmented conditions were highly correlated in RT and accuracy and groups were undifferentiated on RT and accuracy, suggesting again that any possible eye movement differences impacted performance minimally; 3) saccading after stimulus onset would offer little benefit since saccade latency is $200 \mathrm{~ms}$ (Sumner, 2011) and the stimuli appeared for only $250 \mathrm{~ms}$ at unpredictable times during a block (See also Keane et al. (2021a).

RSFC matrices were similar between groups on univariate, multivariate, and Mantel tests; and the shape completion network was similarly strongly integrated in each group during rest. These results argue against a class of alternative explanations: that the Glasser atlas was inappropriate for patient groups (e.g., due to differences in cortical folding), that nicotine intake differences made the neural results incommensurable, or that motion correction was imperfect in patients.

To summarize, employing a well-tested perceptual organization task, we revealed clinically relevant dorsal attention network abnormalities in schizophrenia, orbitofrontal differences in schizophrenia, and more heterogenous and more distributed shape representations across all patients, potentially reflecting compensatory mechanisms. A goal in future research will be to establish a causal role for the dorsal attention network and to consider whether additional networks in patients aid in improving perceptual organization performance. 
medRxiv preprint doi: https://doi.org/10.1101/2022.01.26.22269913; this version posted January 28, 2022. The copyright holder for this preprint (which was not certified by peer review) is the author/funder, who has granted medRxiv a license to display the preprint in perpetuity. It is made available under a CC-BY-NC-ND 4.0 International license .

\section{ABNORMAL BRAIN NETWORKS OF PERCEPTUAL ORGANIZATION}

\section{Extended Data Tables}

\begin{tabular}{|c|c|c|c|c|c|}
\hline $\begin{array}{l}\text { Parcel } \\
\text { Name }\end{array}$ & $\begin{array}{l}\text { Parcel } \\
\text { Number }\end{array}$ & $\begin{array}{l}\text { \% With Difference in } \\
\text { Group Direction }\end{array}$ & $\begin{array}{l}\text { \% With Sig. } \\
\text { Difference }\end{array}$ & Network & $\begin{array}{c}\text { Mean Beta } \\
\text { Difference }[95 \% \text { C }\end{array}$ \\
\hline R_PH & 318 & 95 & 80 & Visual2 & $113.8[77.6,150.1]$ \\
\hline L_MIP & 50 & 95 & 65 & Dorsal-attention & $82.2[43.7,120.6]$ \\
\hline $\bar{R} \_$V4 & 186 & 95 & 55 & Visual2 & $46[21.4,70.7]$ \\
\hline L_IFJp & 80 & 95 & 50 & Frontoparietal & $88[50,126]$ \\
\hline L_PH & 138 & 90 & 80 & Visual2 & $95.6[66.1,125.1]$ \\
\hline$R \_6 r$ & 258 & 90 & 55 & Cingulo-Opercular & $56.4[29.3,83.4]$ \\
\hline R_a24 & 241 & 90 & 45 & Default & $-47.6[-69.7,-25.5]$ \\
\hline L_V3CD & 158 & 85 & 70 & Visual2 & $76.2[45.4,107]$ \\
\hline L_IP1 & 145 & 85 & 65 & Frontoparietal & $65.7[23.5,107.9]$ \\
\hline $\mathrm{R} \_\overline{\mathrm{V}} 3 \mathrm{CD}$ & 338 & 85 & 65 & Visual2 & $64.3[29.3,99.3]$ \\
\hline $\bar{R} \_I P 0$ & 326 & 85 & 60 & Dorsal-attention & $75[44.4,105.6]$ \\
\hline L_PFt & 116 & 85 & 55 & Dorsal-attention & $62.2[28.5,95.8]$ \\
\hline R_PGi & 330 & 85 & 55 & Default & $-43.2[-69.6,-16.8]$ \\
\hline L_LO1 & 20 & 85 & 45 & Visual2 & $64[34.3,93.7]$ \\
\hline L_a24 & 61 & 85 & 45 & Default & $-52[-77.1,-26.9]$ \\
\hline L_IPO & 146 & 85 & 45 & Dorsal-attention & $64.2[26.2,102.3]$ \\
\hline R_LO1 & 200 & 85 & 40 & Visual2 & $55.2[31.1,79.4]$ \\
\hline R_TGd & 311 & 85 & 40 & Default & $-37.8[-58.4,-17.2]$ \\
\hline L_IP2 & 144 & 80 & 65 & Frontoparietal & $74.2[30.3,118.2]$ \\
\hline$L_{-}^{-} 111$ & 91 & 80 & 60 & Frontoparietal & $61.4[32.2,90.6]$ \\
\hline L_AIP & 117 & 80 & 60 & Dorsal-attention & $78.1[39.4,116.8]$ \\
\hline R_MIP & 230 & 80 & 60 & Dorsal-attention & $81.1[38.8,123.5]$ \\
\hline L_V3B & 19 & 80 & 50 & Visual2 & $54.9[22.9,87]$ \\
\hline R_LIPd & 275 & 80 & 50 & Dorsal-attention & $79.3[36.7,122]$ \\
\hline L_V4 & 6 & 80 & 45 & Visual2 & $40.3[11.3,69.3]$ \\
\hline R_IFJp & 260 & 80 & 40 & Frontoparietal & $85.4[36.5,134.2]$ \\
\hline R_d23ab & 214 & 80 & 35 & Default & $-58.3[-92.9,-23.6]$ \\
\hline R_p9-46v & 263 & 75 & 45 & Frontoparietal & $62[29.1,94.8]$ \\
\hline R_AIP & 297 & 75 & 45 & Dorsal-attention & $59.4[23.2,95.5]$ \\
\hline L_IFSa & 82 & 75 & 40 & Frontoparietal & $49.9[22.3,77.4]$ \\
\hline R_PHT & 317 & 75 & 40 & Dorsal-attention & $51.5[19,84]$ \\
\hline L_FST & 157 & 75 & 35 & Visual2 & $45.5[18.7,72.3]$ \\
\hline L_TGd & 131 & 70 & 45 & Default & $-32.5[-53.3,-11.8]$ \\
\hline R_31pv & 215 & 70 & 40 & Default & $-58.5[-95,-22]$ \\
\hline L_LO2 & 21 & 70 & 35 & Visual2 & $48.6[21.5,75.8]$ \\
\hline $\mathrm{R} \_\mathrm{I}$ IP1 & 325 & 65 & 50 & Frontoparietal & $51.7[20.5,83]$ \\
\hline
\end{tabular}

Extended Data Table 2-1. Healthy control results for the 36 "shape completion network coalition" parcels that were significant after FDR correction on the illusory-fragmented task activation analysis. The prefix of each parcel name indicated its hemisphere. The rows were sorted in descending order, first, by the percentage of subjects showing the effect in the group direction (column 3 ) and then, by the percentage of subjects showing significant effects on the 
medRxiv preprint doi: https://doi.org/10.1101/2022.01.26.22269913; this version posted January 28, 2022. The copyright holder for this preprint (which was not certified by peer review) is the author/funder, who has granted medRxiv a license to display the preprint in perpetuity. It is made available under a CC-BY-NC-ND 4.0 International license.

\section{ABNORMAL BRAIN NETWORKS OF PERCEPTUAL ORGANIZATION}

individual subject analysis (column 4). The fifth column indicates a parcel's functional network. In the final column, we show the average task activation difference, with more positive values indicating more illusory relative to fragmented activation. 
medRxiv preprint doi: https://doi.org/10.1101/2022.01.26.22269913; this version posted January 28, 2022. The copyright holder for this preprint (which was not certified by peer review) is the author/funder, who has granted medRxiv a license to display the preprint in perpetuity. It is made available under a CC-BY-NC-ND 4.0 International license .

\section{ABNORMAL BRAIN NETWORKS OF PERCEPTUAL ORGANIZATION}

\begin{tabular}{|c|c|c|c|c|c|}
\hline $\begin{array}{l}\text { Parcel } \\
\text { Name }\end{array}$ & $\begin{array}{l}\text { Parcel } \\
\text { Number }\end{array}$ & $\begin{array}{l}\text { \% With Difference } \\
\text { in Group } \\
\text { Direction }\end{array}$ & $\begin{array}{l}\% \text { With Sig. } \\
\text { Difference }\end{array}$ & Network & $\begin{array}{c}\text { Mean Beta Difference } \\
{[95 \% \mathrm{Cl}]}\end{array}$ \\
\hline L_PFt & 116 & 93 & 67 & Dorsal-attention & $70.1[44,96.2]$ \\
\hline L_IFSa & 82 & 87 & 40 & Frontoparietal & $45.1[19.9,70.3]$ \\
\hline L_IP2 & 144 & 87 & 40 & Frontoparietal & $33.8[-15.5,83.1]$ \\
\hline $\mathrm{R} \_\mathrm{PH}$ & 318 & 80 & 60 & $\begin{array}{l}\text { Visual2 } \\
\text { Cingulo- }\end{array}$ & $84.9[47.2,122.7]$ \\
\hline$R \_6 r$ & 258 & 80 & 53 & Opercular & $46[-0.5,92.6]$ \\
\hline R_p9-46v & 263 & 80 & 47 & Frontoparietal & $31.5[-16.1,79.1]$ \\
\hline $\overrightarrow{\mathrm{L}}$ IFJp & 80 & 80 & 40 & Frontoparietal & $51.2[\quad-8,110.3]$ \\
\hline R_V4 & 186 & 80 & 33 & Visual2 & $26.1[-10.7,62.8]$ \\
\hline R_MIP & 230 & 73 & 67 & Dorsal-attention & $18.7[-45.4,82.8]$ \\
\hline L_PH & 138 & 73 & 60 & Visual2 & $46.7[2.2,91.1]$ \\
\hline R_LIPd & 275 & 73 & 53 & Dorsal-attention & $39.5[-28.1,107.1]$ \\
\hline L_LO2 & 21 & 73 & 47 & Visual2 & $46.1[6.3,85.8]$ \\
\hline L_MIP & 50 & 73 & 47 & Dorsal-attention & $22[-41.1,85.1]$ \\
\hline L_AIP & 117 & 73 & 47 & Dorsal-attention & $25.6[-18.9,70.1]$ \\
\hline R_PHT & 317 & 73 & 47 & Dorsal-attention & $47.1[7.6,86.7]$ \\
\hline R_LO1 & 200 & 73 & 33 & Visual2 & $27.1[-6.1,60.3]$ \\
\hline R_V3CD & 338 & 73 & 33 & Visual2 & $29.4[-0.9,59.6]$ \\
\hline$L_{-} 111$ & 91 & 67 & 47 & Frontoparietal & $28.4[-36.6,93.3]$ \\
\hline L_FST & 157 & 67 & 47 & Visual2 & $41[-12,94.1]$ \\
\hline R_IFJp & 260 & 67 & 47 & Frontoparietal & $54.4[-3.2,111.9]$ \\
\hline R_AIP & 297 & 67 & 47 & Dorsal-attention & $16.8[-33.3,66.8]$ \\
\hline L_V4 & 6 & 67 & 40 & Visual2 & $17.2[-20.6,55.1]$ \\
\hline L_V3CD & 158 & 67 & 40 & Visual2 & $13.6[-34.7,61.9]$ \\
\hline R_PGi & 330 & 67 & 40 & Default & $-17.6[-43.7,8.5]$ \\
\hline L_a24 & 61 & 67 & 7 & Default & $3[-18.4,24.5]$ \\
\hline R_31pv & 215 & 67 & 7 & Default & $-5.7[-39.1,27.6]$ \\
\hline L_IPO & 146 & 60 & 47 & Dorsal-attention & $12.7[-41.5,66.9]$ \\
\hline L_IP1 & 145 & 60 & 40 & Frontoparietal & $13.7[-32.5,59.9]$ \\
\hline L_LO1 & 20 & 60 & 20 & Visual2 & $4.5[-32,41.1]$ \\
\hline R_d23ab & 214 & 60 & 20 & Default & $34.2[-11.3,79.8]$ \\
\hline L_V3B & 19 & 60 & 13 & Visual2 & $8[-33.3,49.3]$ \\
\hline R_TGd & 311 & 60 & 13 & Default & $2.2[-26.9,31.3]$ \\
\hline L_TGd & 131 & 53 & 40 & Default & $21.2[-7.3,49.7]$ \\
\hline R_IPO & 326 & 53 & 20 & Dorsal-attention & $-14.6[-55.5,26.2]$ \\
\hline R_IP1 & 325 & 53 & 13 & Frontoparietal & $13.5[-44,70.9]$ \\
\hline R_a24 & 241 & 53 & 7 & Default & $-1.2[-26,23.5]$ \\
\hline
\end{tabular}

Extended Data Table 2-2. The table is the same as $\mathrm{S} 1$ except that results for the same 36 regions are shown for bipolar disorder patients. As can be seen, there appeared to be an increased reliance on the cognitive control networks compared to schizophrenia. 
medRxiv preprint doi: https://doi.org/10.1101/2022.01.26.22269913; this version posted January 28, 2022. The copyright holder for this preprint (which was not certified by peer review) is the author/funder, who has granted medRxiv a license to display the preprint in perpetuity. It is made available under a CC-BY-NC-ND 4.0 International license .

\section{ABNORMAL BRAIN NETWORKS OF PERCEPTUAL ORGANIZATION}

\begin{tabular}{|c|c|c|c|c|c|}
\hline $\begin{array}{l}\text { Parcel } \\
\text { Name }\end{array}$ & $\begin{array}{l}\text { Parcel } \\
\text { Number }\end{array}$ & $\begin{array}{l}\% \text { With Difference } \\
\text { in Group Direction }\end{array}$ & $\begin{array}{l}\text { \% With Sig. } \\
\text { Difference }\end{array}$ & Network & $\begin{array}{l}\text { Mean Beta } \\
\text { Difference }[95 \% \mathrm{Cl}]\end{array}$ \\
\hline L_PH & 138 & 81 & 50 & Visual2 & $58.3[25,91.6]$ \\
\hline $\mathrm{R} \_\mathrm{PH}$ & 318 & 81 & 38 & Visual2 & $62.9[23,102.8]$ \\
\hline L_V3CD & 158 & 75 & 69 & Visual2 & $52[13.3,90.8]$ \\
\hline L_LO1 & 20 & 75 & 50 & Visual2 & $31.8[-8.3,71.8]$ \\
\hline L_LO2 & 21 & 75 & 50 & Visual2 & $51.5[13.1,89.8]$ \\
\hline L_IP2 & 144 & 75 & 38 & Frontoparietal & $34.8[-5,74.6]$ \\
\hline L_IP1 & 145 & 75 & 38 & Frontoparietal & $43.3[8.5,78.2]$ \\
\hline L_IFJp & 80 & 75 & 31 & Frontoparietal & $49.1[10.9,87.3]$ \\
\hline L_V4 & 6 & 69 & 38 & Visual2 & $21.7[-18.2,61.5]$ \\
\hline R_V3CD & 338 & 69 & 38 & Visual2 & $45.1[3.3,86.8]$ \\
\hline L_IFSa & 82 & 69 & 31 & Frontoparietal & $28.7[-13.1,70.4]$ \\
\hline R_IFJp & 260 & 69 & 31 & Frontoparietal & $50.3[5.9,94.7]$ \\
\hline R_LIPd & 275 & 69 & 31 & Dorsal-attention & $29.3[-7.1,65.8]$ \\
\hline R_p9-46v & 263 & 69 & 19 & Frontoparietal & $20.1[-14,54.1]$ \\
\hline L_a24 & 61 & 63 & 44 & Default & $-16.4[-58.3,25.6]$ \\
\hline R_V4 & 186 & 63 & 44 & Visual2 & $26.4[-15.8,68.7]$ \\
\hline R_a24 & 241 & 63 & 44 & Default & $-24[-52.9,4.9]$ \\
\hline R_IP1 & 325 & 63 & 44 & Frontoparietal & $32.9[-3.4,69.1]$ \\
\hline R_LO1 & 200 & 63 & 38 & Visual2 & $43.8[-1.8,89.3]$ \\
\hline R_IPO & 326 & 63 & 38 & Dorsal-attention & $18.5[-17.2,54.2]$ \\
\hline L_IPO & 146 & 63 & 31 & Dorsal-attention & $30.7[-4.2,65.6]$ \\
\hline L_V3B & 19 & 63 & 19 & Visual2 & $5.7[-26.2,37.6]$ \\
\hline R_6r & 258 & 63 & 19 & Cingulo-Opercular & $3.8[-29.4,37]$ \\
\hline$R \_d 23 a b$ & 214 & 63 & 13 & Default & $22.5[-8,53]$ \\
\hline L_TGd & 131 & 56 & 38 & Default & $2.4[-32.6,37.5]$ \\
\hline R_PGi & 330 & 56 & 38 & Default & $-21.4[-63.8,21]$ \\
\hline L_MIP & 50 & 56 & 31 & Dorsal-attention & $20[-13.8,53.8]$ \\
\hline R_TGd & 311 & 56 & 25 & Default & $10.7[-23.4,44.8]$ \\
\hline L_11I & 91 & 56 & 19 & Frontoparietal & $4.9[-27.6,37.4]$ \\
\hline L_AIP & 117 & 56 & 19 & Dorsal-attention & $8.8[-32,49.7]$ \\
\hline R_31pv & 215 & 56 & 0 & Default & $17.3[-17.7,52.3]$ \\
\hline L_PFt & 116 & 50 & 19 & Dorsal-attention & $9.9[-21.9,41.8]$ \\
\hline R_MIP & 230 & 50 & 19 & Dorsal-attention & $0[-26.1,26.1]$ \\
\hline R_PHT & 317 & 50 & 19 & Dorsal-attention & $4.7[-27.2,36.6]$ \\
\hline L_FST & 157 & 50 & 13 & Visual2 & $22.2[-19.9,64.2]$ \\
\hline R_AIP & 297 & 50 & 13 & Dorsal-attention & $-3.3[-26.3,19.7]$ \\
\hline
\end{tabular}

Extended Data Table 2-3. The table is the same as S1 except that results are shown for schizophrenia patients. As can be seen, there is less pronounced shape completion modulation, less reliance on the dorsal attention network, and an overall different ordering of regions than in controls. 
medRxiv preprint doi: https://doi.org/10.1101/2022.01.26.22269913; this version posted January 28, 2022. The copyright holder for this preprint (which was not certified by peer review) is the author/funder, who has granted medRxiv a license to display the preprint in perpetuity. It is made available under a CC-BY-NC-ND 4.0 International license.

ABNORMAL BRAIN NETWORKS OF PERCEPTUAL ORGANIZATION 
medRxiv preprint doi: https://doi.org/10.1101/2022.01.26.22269913; this version posted January 28, 2022. The copyright holder for this preprint (which was not certified by peer review) is the author/funder, who has granted medRxiv a license to display the preprint in perpetuity. It is made available under a CC-BY-NC-ND 4.0 International license .

ABNORMAL BRAIN NETWORKS OF PERCEPTUAL ORGANIZATION

\section{References}

Addington, D., Addington, J., Maticka-Tyndale, E., 1993. Assessing depression in schizophrenia: The Calgary Depression Scale. The British Journal of Psychiatry 163, 3944.

Alda, M., 2004. The phenotypic spectra of bipolar disorder, in:. Presented at the European Neuropsychopharmacology, pp. S94-9. doi:10.1016/j.euroneuro.2004.03.006

American Psychiatric Association, 2013. Diagnostic and statistical manual of mental disorders, 5 ed.

Anticevic, A., Cole, M.W., Repovs, G., Murray, J.D., Brumbaugh, M.S., Winkler, A.M., Savic, A., Krystal, J.H., Pearlson, G.D., Glahn, D.C., 2014. Characterizing thalamo-cortical disturbances in schizophrenia and bipolar illness. Cerebral Cortex 24, 3116-3130. doi:10.1093/cercor/bht165

Bar, M., 2003. A cortical mechanism for triggering top-down facilitation in visual object recognition. J Cogn Neurosci 15, 600-609. doi:10.1162/089892903321662976

Beck, J., 1966. Effect of orientation and of shape similarity on perceptual grouping. Perception \& Psychophysics 1, 300-302.

Benjamini, Y., Hochberg, J., 1995. Controlling the false discovery rate: A practical and powerful approach to multiple testing. Journal of the Royal Statistical Society Series BMethodological 57, 289-300.

Berkovitch, L., Dehaene, S., Gaillard, R., 2017. Disruption of Conscious Access in Schizophrenia. Trends Cogn Sci (Regul Ed) 21, 878-892. doi:10.1016/j.tics.2017.08.006

Berkovitch, L., Del Cul, A., Maheu, M., Dehaene, S., 2018. Impaired conscious access and abnormal attentional amplification in schizophrenia. Neuroimage Clin 18, 835-848. doi:10.1016/j.nicl.2018.03.010

Bollini, P., Pampallona, S., Tibaldi, G., Kupelnick, B., Munizza, C., 1999. Effectiveness of antidepressants - Meta-analysis of dose-effect relationships in randomised clinical trials. $\mathrm{Br}$ J Psychiatry 174, 297-303.

Canivez, G.L., Watkins, M.W., 2010. Investigation of the factor structure of the Wechsler Adult Intelligence Scale-Fourth Edition (WAIS-IV): Exploratory and higher order factor analyses. Psychological Assessment 22, 827-836. doi:10.1037/a0020429

Cannon-Spoor, H.E., Potkin, S.G., Wyatt, R.J., 1982. Measurement of premorbid adjustment in chronic schizophrenia. Schizophr Bull 8, 470-484.

Cassidy, F., Ahearn, E.P., Carroll, B.J., 2001. Substance abuse in bipolar disorder. Bipolar Disorders 3, 181-188.

Ciric, R., Wolf, D.H., Power, J.D., Roalf, D.R., Baum, G.L., Ruparel, K., Shinohara, R.T., Elliott, M.A., Eickhoff, S.B., Davatzikos, C., Gur, R.C., Gur, R.E., Bassett, D.S., Satterthwaite, T.D., 2017. Benchmarking of participant-level confound regression strategies for the control of motion artifact in studies of functional connectivity. Neuroimage 154, 174-187. doi:10.1016/j.neuroimage.2017.03.020

Cole, M.W., Ito, T., Bassett, D.S., Schultz, D.H., 2016. Activity flow over resting-state networks shapes cognitive task activations. Nature Neuroscience 19, 1718-1726.

doi:10.1038/nn.4406 
medRxiv preprint doi: https://doi.org/10.1101/2022.01.26.22269913; this version posted January 28, 2022. The copyright holder for this preprint (which was not certified by peer review) is the author/funder, who has granted medRxiv a license to display the preprint in perpetuity. It is made available under a CC-BY-NC-ND 4.0 International license .

ABNORMAL BRAIN NETWORKS OF PERCEPTUAL ORGANIZATION

Cox, M.A., Schmid, M.C., Peters, A.J., Saunders, R.C., Leopold, D.A., Maier, A., 2013.

Receptive field focus of visual area V4 neurons determines responses to illusory surfaces. Proc Natl Acad Sci USA 110, 17095-17100. doi:10.1073/pnas.1310806110//DCSupplemental

Cremers, H.R., Wager, T.D., Yarkoni, T., 2017. The relation between statistical power and inference in fMRI. PLOS ONE 12, e0184923. doi:10.1371/journal.pone.0184923

Damaraju, E., Allen, E.A., Belger, A., Ford, J.M., McEwen, S., Mathalon, D.H., Mueller, B.A., Pearlson, G.D., Potkin, S.G., Preda, A., Turner, J.A., Vaidya, J.G., van Erp, T.G., Calhoun, V.D., 2014. Neurolmage: Clinical. Neuroimage Clin 5, 298-308. doi:10.1016/j.nicl.2014.07.003

Diniz-Filho, J.A.F., Soares, T.N., Lima, J.S., Dobrovolski, R., Landeiro, V.L., Telles, M.P. de C., Rangel, T.F., Bini, L.M., 2013. Mantel test in population genetics. Genetics and Molecular Biology 36, 475-485. doi:10.1590/S1415-47572013000400002

Dixon, L., 1999. Dual diagnosis of substance abuse in schizophrenia: prevalence and impact on outcomes. Schizophr Res 35 Suppl, S93-100.

Dunayevich, E., Keck, P.E., 2000. Prevalence and description of psychotic features in bipolar mania. Curr Psychiatry Rep 2, 286-290. doi:10.1007/s11920-000-0069-4

Etzel, J.A., Braver, T.S., 2013. MVPA permutation schemes: Permutation testing in the land of cross-validation, in:. Presented at the Proceedings - 2013 3rd International Workshop on Pattern Recognition in Neuroimaging, PRNI 2013, pp. 140-143. doi:10.1109/PRNI.2013.44

Foxe, J.J., Doniger, G.M., Javitt, D.C., 2001. Early visual processing deficits in schizophrenia: impaired P1 generation revealed by high-density electrical mapping. Neuroreport 12, 3815-3820.

Foxe, J.J., Murray, M.M., Javitt, D.C., 2005. Filling-in in schizophrenia: a high-density electrical mapping and source-analysis investigation of illusory contour processing. Cereb Cortex 15 , 1914-1927. doi:10.1093/cercor/bhi069

Gardner, D.M., Murphy, A.L., O'Donnell, H., Centorrino, F., Baldessarini, R.J., 2010. International Consensus Study of Antipsychotic Dosing. Am J Psychiatry 167, 686-693.

Glasser, M.F., Coalson, T.S., Robinson, E.C., Hacker, C.D., Harwell, J., Yacoub, E., Uğurbil, K., Andersson, J., Beckmann, C.F., Jenkinson, M., Smith, S.M., Van Essen, D.C., 2016. A multi-modal parcellation of human cerebral cortex. Nature 536, 171-178. doi:10.1038/nature18933

Glasser, M.F., Sotiropoulos, S.N., Wilson, J.A., Coalson, T.S., Fischl, B., Andersson, J.L., Xu, J., Jbabdi, S., Webster, M., Polimeni, J.R., Van Essen, D.C., Jenkinson, M., Consortium, F.T.W.-M.H., 2013. The minimal preprocessing pipelines for the Human Connectome Project. Neuroimage 80, 105-124. doi:10.1016/j.neuroimage.2013.04.127

Greene, A.S., Gao, S., Scheinost, D., Constable, R.T., 2018. Task-induced brain state manipulation improves prediction of individual traits. Nat Comms 9, 2807-13. doi:10.1038/s41467-018-04920-3

Grent-'t-Jong, T., Gajwani, R., Gross, J., Gumley, A.I., Krishnadas, R., Lawrie, S.M., Schwannauer, M., Schultze-Lutter, F., Uhlhaas, P.J., 2020. Association of Magnetoencephalographically Measured High-Frequency Oscillations in Visual Cortex With Circuit Dysfunctions in Local and Large-scale Networks During Emerging Psychosis. JAMA Psychiatry. doi:10.1001/jamapsychiatry.2020.0284

Grzeczkowski, L., Clarke, A.M., Francis, G., Mast, F.W., Herzog, M.H., 2017. About individual differences in vision. Vision Research 141, 282-292. doi:10.1016/j.visres.2016.10.006 
medRxiv preprint doi: https://doi.org/10.1101/2022.01.26.22269913; this version posted January 28, 2022. The copyright holder for this preprint (which was not certified by peer review) is the author/funder, who has granted medRxiv a license to display the preprint in perpetuity. It is made available under a CC-BY-NC-ND 4.0 International license .

ABNORMAL BRAIN NETWORKS OF PERCEPTUAL ORGANIZATION

Hahn, B., Robinson, B.M., Leonard, C.J., Luck, S.J., Gold, J.M., 2018. Posterior Parietal Cortex Dysfunction Is Central to Working Memory Storage and Broad Cognitive Deficits in Schizophrenia. Journal of Neuroscience 38, 8378-8387. doi:10.1523/JNEUROSCI.091318.2018

Halgren, E., Mendola, J., Chong, C.D.R., Dale, A.M., 2003. Cortical activation to illusory shapes as measured with magnetoencephalography. Neuroimage 18, 1001-1009.

Hearne, L.J., Mill, R.D., Keane, B.P., Repovs, G., Anticevic, A., Cole, M.W., 2021. Activity flow underlying abnormalities in brain activations and cognition in schizophrenia. Science Advances 1-13. doi:10.1126/sciadv.abf2513

Heatherton, T.F., Kozlowski, L.T., Frecker, R.C., Fagerstrom, K.O., 1991. The Fagerstrom Test for Nicotine Dependence - a Revision of the Fagerstrom Tolerance Questionnaire. Br J Addict 86, 1119-1127. doi:10.1111/j.1360-0443.1991.tb01879.x

Hentschke, H., 2021. hhentschke/measures-of-effect-size-toolbox (https://github.com/hhentschke/measures-of-effect-size-toolbox). GitHub.

Horga, G., Cassidy, C.M., Xu, X., Moore, H., Slifstein, M., Van Snellenberg, J.X., AbiDargham, A., 2016. Dopamine-related disruption of functional topography of striatal connections in unmedicated patients with schizophrenia. JAMA Psychiatry 73, 862-870. doi:10.1001/jamapsychiatry.2016.0178

Ji, J.L., Spronk, M., Kulkarni, K., Repovs, G., Anticevic, A., Cole, M.W., 2019. Mapping the human brain's cortical-subcortical functional network organization. Neuroimage 185, 3557. doi:10.1016/j.neuroimage.2018.10.006

Kahnt, T., Heinzle, J., Park, S.Q., Haynes, J.-D., 2010. The neural code of reward anticipation in human orbitofrontal cortex. Proceedings of the National Academy of Sciences 107, 6010-6015. doi:10.1073/pnas.0912838107

Kay, S.R., Fiszbein, A., Opler, L.A., 1987. The Positive and Negative Syndrome Scale (PANSS) for schizophrenia. Schizophr Bull 13, 261-276.

Keane, B.P., 2018. Contour interpolation: A case study in Modularity of Mind. Cognition 174, 1-18. doi:10.1016/j.cognition.2018.01.008

Keane, B.P., Barch, D.M., Mill, R.D., Silverstein, S.M., Krekelberg, B., Cole, M.W., $2021 a$. Brain network mechanisms of visual shape completion. Neuroimage 236, 118069. doi:10.1016/j.neuroimage.2021.118069

Keane, B.P., Erlikhman, G., Serody, M., Silverstein, S.M., 2021b. A brief psychometric test reveals robust shape completion deficits in schizophrenia that are less severe in bipolar disorder. Schizophr Res 240, 78-80. doi:10.1016/j.schres.2021.12.015

Keane, B.P., Joseph, J., Silverstein, S.M., 2014. Late, not early, stages of Kanizsa shape perception are compromised in schizophrenia. Neuropsychologia 56, 302-311. doi:10.1016/j.neuropsychologia.2014.02.001

Keane, B.P., Lu, H., Papathomas, T.V., Silverstein, S.M., Kellman, P.J., 2012. Is interpolation cognitively encapsulated? Measuring the effects of belief on Kanizsa shape discrimination and illusory contour formation. Cognition 123, 404-418. doi:10.1016/j.cognition.2012.02.004

Keane, B.P., Paterno, D., Kastner, S., Krekelberg, B., Silverstein, S.M., 2019. Intact illusory contour formation but equivalently impaired visual shape completion in first- and laterepisode schizophrenia. J Abnorm Psychol 128, 57-68. doi:10.1037/abn0000384

Kellman, P.J., Shipley, T., 1991. A theory of visual interpolation in object perception. Cogn Psychol 23, 141. 
medRxiv preprint doi: https://doi.org/10.1101/2022.01.26.22269913; this version posted January 28, 2022. The copyright holder for this preprint (which was not certified by peer review) is the author/funder, who has granted medRxiv a license to display the preprint in perpetuity. It is made available under a CC-BY-NC-ND 4.0 International license .

\section{ABNORMAL BRAIN NETWORKS OF PERCEPTUAL ORGANIZATION}

Keshavan, M.S., Morris, D.W., Sweeney, J.A., Pearlson, G., Thaker, G., Seidman, L.J., Eack, S.M., Tamminga, C., 2011. A dimensional approach to the psychosis spectrum between bipolar disorder and schizophrenia: The Schizo-Bipolar Scale. Schizophr Res 133, 250254. doi:10.1016/j.schres.2011.09.005

Kontsevich, L.L., Tyler, C.W., 1999. Bayesian adaptive estimation of psychometric slope and threshold. Vision Research 39, 2729-2737.

Kozak, M.J., Cuthbert, B.N., 2016. The NIMH Research Domain Criteria Initiative: Background, Issues, and Pragmatics. Psychophysiology 53, 286-297. doi:10.1111/psyp.12518

Lichtenstein, P., Yip, B.H., Björk, C., Pawitan, Y., Cannon, T.D., Sullivan, P.F., Hultman, C.M., 2009. Common genetic determinants of schizophrenia and bipolar disorder in Swedish families: a population-based study. Lancet 373, 234-239. doi:10.1016/S01406736(09)60072-6

Loftus, 1994. Using confidence intervals in within-subject designs. Psychon Bull Rev 1, 476490.

Ma, Q., Tang, Y., Wang, F., Liao, X., Jiang, X., Wei, S., Mechelli, A., He, Y., Xia, M., 2020. Transdiagnostic Dysfunctions in Brain Modules Across Patients with Schizophrenia, Bipolar Disorder, and Major Depressive Disorder: A Connectome-Based Study. Schizophr Bull 46, 699-712. doi:10.1093/schbul/sbz111

Maertens, M., Pollmann, S., 2005. fMRI reveals a common neural substrate of illusory and real contours in V1 after perceptual learning. J Cogn Neurosci 17, 1553-1564. doi:10.1162/089892905774597209

Malikovic, A., Amunts, K., Schleicher, A., Mohlberg, H., Kujovic, M., Palomero-Gallagher, N., Eickhoff, S.B., Zilles, K., 2016. Cytoarchitecture of the human lateral occipital cortex: mapping of two extrastriate areas hOc4la and hOc4lp. Brain Struct Funct 221, 1877-1897. doi:10.1007/s00429-015-1009-8

Mantel, N., 1967. The Detection of Disease Clustering and a Generalized Regression Approach. Cancer Research 27, 209-220.

Mill, R.D., Gordon, B.A., Balota, D.A., Cole, M.W., 2020. Predicting dysfunctional age-related task activations from resting-state network alterations. Neuroimage 117167-37. doi:10.1016/j.neuroimage.2020.117167

Mur, M., Bandettini, P.A., Kriegeskorte, N., 2009. Revealing representational content with pattern-information fMRI--an introductory guide. Soc Cogn Affect Neurosci 4, 101-109. doi:10.1093/scan/nsn044

Murray, M.M., Imber, M.L., Javitt, D.C., Foxe, J.J., 2006. Boundary Completion Is Automatic and Dissociable from Shape Discrimination. Journal of Neuroscience 26, 12043-12054. doi:10.1523/JNEUROSCI.3225-06.2006

Nakamura, M., Nestor, P.G., Levitt, J.J., Cohen, A.S., Kawashima, T., Shenton, M.E., McCarley, R.W., 2008. Orbitofrontal volume deficit in schizophrenia and thought disorder. Brain 131, 180-195. doi:10.1093/brain/awm265

Noble, S., Mejia, A.F., Zalesky, A., Scheinost, D., 2021. Leveling up: improving power in fMRI by moving beyond cluster-level inference. Science Advances 2021.09.23.461354. doi:10.1101/2021.09.23.461354

O'Donnell, B.F., Swearer, J.M., Smith, L.T., Nestor, P.G., Shenton, M.E., Mccarley, R.W., 1996. Selective deficits in visual perception and recognition in schizophrenia. Am J Psychiatry 153, 687-692.

Peirce, J.W., 2007. PsychoPy-Psychophysics software in Python. J Neurosci Methods 162, 8-13. doi:10.1016/j.jneumeth.2006.11.017 
medRxiv preprint doi: https://doi.org/10.1101/2022.01.26.22269913; this version posted January 28, 2022. The copyright holder for this preprint (which was not certified by peer review) is the author/funder, who has granted medRxiv a license to display the preprint in perpetuity. It is made available under a CC-BY-NC-ND 4.0 International license .

\section{ABNORMAL BRAIN NETWORKS OF PERCEPTUAL ORGANIZATION}

Pelli, D.G., 1997. The VideoToolbox software for visual psychophysics: transforming numbers into movies. Spat Vis 10, 437-442.

Pillow, J., Rubin, N., 2002. Perceptual completion across the vertical meridian and the role of early visual cortex. Neuron 33, 805-813.

Power, J.D., Barnes, K.A., Snyder, A.Z., Schlaggar, B.L., Petersen, S.E., 2012. Spurious but systematic correlations in functional connectivity MRI networks arise from subject motion. Neuroimage 59, 2142-2154. doi:10.1016/j.neuroimage.2011.10.018

Raffard, S., Bayard, S., 2012. Understanding the executive functioning heterogeneity in schizophrenia. Brain Cogn 79, 60-69. doi:10.1016/j.bandc.2012.01.008

Reid, A.T., Headley, D.B., Mill, R.D., Sanchez-Romero, R., Uddin, L.Q., Marinazzo, D., Lurie, D.J., Valdés-Sosa, P.A., Hanson, S.J., Biswal, B.B., Calhoun, V., Poldrack, R.A., Cole, M.W., 2019. Advancing functional connectivity research from association to causation. Nature Neuroscience 22, 1751-1760. doi:10.1038/s41593-019-0510-4

Rhee, T.G., Olfson, M., Nierenberg, A.A., Wilkinson, S.T., 2020. 20-Year Trends in the Pharmacologic Treatment of Bipolar Disorder by Psychiatrists in Outpatient Care Settings. Am J Psychiatry 177, 706-715. doi:10.1176/appi.ajp.2020.19091000

Ringach, D., Shapley, R., 1996. Spatial and temporal properties of illusory contours and amodal boundary completion. Vision Research 36, 3037-3050.

Rosenberg, M.D., Finn, E.S., Scheinost, D., Papademetris, X., Shen, X., Constable, R.T., Chun, M.M., 2015. A neuromarker of sustained attention from whole-brain functional connectivity. Nature Neuroscience 19, 165-171. doi:10.1038/nn.4179

Schallmo, M.P., Sponheim, S.R., Olman, C.A., 2015. Reduced contextual effects on visual contrast perception in schizophrenia and bipolar affective disorder. Psychological Medicine 1-11. doi:10.1017/S0033291715001439

Schechter, I., Butler, P.D., Jalbrzikowski, M., Pasternak, R., Saperstein, A.M., Javitt, D.C., 2006. A new dimension of sensory dysfunction: stereopsis deficits in schizophrenia. Biol Psychiatry 60, 1282-1284. doi:10.1016/j.biopsych.2006.03.064

Schultz, D.H., Ito, T., Solomyak, L.I., Chen, R.H., Mill, R.D., Anticevic, A., Cole, M.W., 2018. Global connectivity of the fronto-parietal cognitive control network is related to depression symptoms in the general population. Netw Neurosci 3, 107-123.

doi:10.1162/netn_a_00056

Schulz, M.-A., Yeo, B.T.T., Vogelstein, J.T., Mourao-Miranada, J., Kather, J.N., Kording, K., Richards, B., Bzdok, D., 2020. Different scaling of linear models and deep learning in UKBiobank brain images versus machine-learning datasets. Nat Comms 11, 4238-15. doi:10.1038/s41467-020-18037-z

Shen, X., Finn, E.S., Scheinost, D., Rosenberg, M.D., Chun, M.M., Papademetris, X., Constable, R.T., 2017. Using connectome-based predictive modeling to predict individual behavior from brain connectivity. Nat Protoc 12, 506-518. doi:10.1038/nprot.2016.178

Shipley, W.C., Gruber, C.P., Martin, T.A., Klein, A.M., 2009. Shipley-2. Western Psychological Services, Los Angeles.

Silverstein, S.M., Keane, B.P., 2011. Perceptual organization impairment in schizophrenia and associated brain mechanisms: Review of research from 2005 to 2010 . Schizophr Bull 37, 690-699. doi:10.1093/schbul/sbr052

Spencer, K.M., Ghorashi, S., 2014. Oscillatory Dynamics of Gestalt Perception in Schizophrenia Revisited. Front. Psychol.

Spencer, K.M., Nestor, P.G., Perlmutter, R., Niznikiewicz, M.A., Klump, M.C., Frumin, M., Shenton, M.E., McCarley, R.W., 2004. Neural synchrony indexes disordered perception 
medRxiv preprint doi: https://doi.org/10.1101/2022.01.26.22269913; this version posted January 28, 2022. The copyright holder for this preprint (which was not certified by peer review) is the author/funder, who has granted medRxiv a license to display the preprint in perpetuity. It is made available under a CC-BY-NC-ND 4.0 International license .

\section{ABNORMAL BRAIN NETWORKS OF PERCEPTUAL ORGANIZATION}

and cognition in schizophrenia. Proc Natl Acad Sci USA 101, 17288-17293. doi:10.1073/pnas.0406074101

Spronk, M., Keane, B.P., Ito, T., Kulkarni, K., Ji, J.L., Anticevic, A., Cole, M.W., 2020. A WholeBrain and Cross-Diagnostic Perspective on Functional Brain Network Dysfunction. Cerebral Cortex. doi:10.1093/cercor/bhaa242

Sripada, C., Angstadt, M., Rutherford, S., Taxali, A., Shedden, K., 2020. Toward a "treadmill test" for cognition: Improved prediction of general cognitive ability from the task activated brain. Hum Brain Mapp 41, 3186-3197. doi:10.1002/hbm.25007

Sumner, P., 2011. Determinants of saccade latency, in: Liversedge, S., Gilchrist, I., Everling, S. (Eds.), The Oxford Handbook of Eye Movements. New York, pp. 411-424.

Valente, G., Castellanos, A.L., Hausfeld, L., De Martino, F., Formisano, E., 2021. Crossvalidation and permutations in MVPA: Validity of permutation strategies and power of cross-validation schemes. Neuroimage 238, 118145.

doi:10.1016/j.neuroimage.2021.118145

van Mastrigt, S., Addington, J., 2002. Assessment of premorbid function in first-episode schizophrenia: modifications to the Premorbid Adjustment Scale. J Psychiatry Neurosci.

Wallwork, R.S., Fortgang, R., Hashimoto, R., Weinberger, D.R., Dickinson, D., 2012. Searching for a consensus five-factor model of the Positive and Negative Syndrome Scale for schizophrenia. Schizophr Res 137, 246-250. doi:10.1016/j.schres.2012.01.031

Wokke, M.E., Vandenbroucke, A.R.E., Scholte, H.S., Lamme, V.A.F., 2013. Confuse your illusion: feedback to early visual cortex contributes to perceptual completion. Psychological Science 24, 63-71. doi:10.1177/0956797612449175

Wynn, J.K., Roach, B.J., Lee, J., Horan, W.P., Ford, J.M., Jimenez, A.M., Green, M.F., 2015. EEG Findings of Reduced Neural Synchronization during Visual Integration in Schizophrenia. PLOS ONE 10, e0119849. doi:10.1371/journal.pone.0119849.s001

Young, R.C., Biggs, J.T., Ziegler, V.E., Meyer, D.A., 1978. A rating scale for mania: reliability, validity and sensitivity. Br J Psychiatry Nov, 429-435.

Zhang, J., Kucyi, A., Raya, J., Nielsen, A.N., Nomi, J.S., Damoiseaux, J.S., Greene, D.J., Horovitz, S.G., Uddin, L.Q., Whitfield-Gabrieli, S., 2021. What have we really learned from functional connectivity in clinical populations? Neuroimage 242, 118466. doi:10.1016/j.neuroimage.2021.118466

Zhang, Y., Yang, Y., 2015. Cross-validation for selecting a model selection procedure. Journal of Econometrics 187, 95-112. doi:10.1016/j.jeconom.2015.02.006 